\title{
The proximal tubular a7 nicotinic acetylcholine receptor attenuates ischemic acute kidney injury through Akt/PKC signaling-mediated $\mathrm{HO}-1$ induction
}

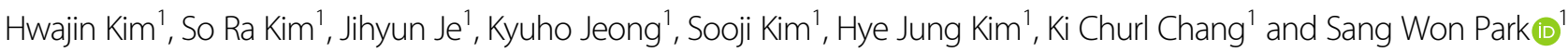

\begin{abstract}
Activation of the a7 nicotinic acetylcholine receptor (a7nAChR) has been shown to attenuate excessive inflammation by inhibiting proinflammatory cytokines during ischemia-reperfusion (IR) injury; however, the underlying kidneyspecific molecular mechanisms remain unclear. The protective action of a7nAChR against renal IR injury was investigated using a selective a7nAChR agonist and antagonist. a7nAChR activation reduced plasma creatinine levels and tubular cell damage, whereas a7nAChR inhibition aggravated the IR-induced phenotype. a7nAChR activation decreased neutrophil infiltration and proinflammatory cytokine expression, increased heme oxygenase-1 (HO-1) expression, and reduced proximal tubular apoptosis after IR as shown by terminal deoxynucleotidyl transferase dUTP nick-end labeling staining and caspase-3 cleavage. In this study, we first showed that a7nAChR activation in the proximal tubules induced HO-1 expression through the phosphoinositide 3-kinase (PI3K)/Akt and protein kinase C (PKC) signaling pathway in vivo in renal IR mice and in vitro in proximal tubular cells. Chemical inhibitors of PKC or PI3K/Akt and small interfering RNA-mediated PKC silencing confirmed the signal specificity of a7nAChR-mediated HO-1 induction in the proximal tubular cells. a7nAChR activation inhibited high-mobility group box 1 release by inducing $\mathrm{HO}_{-1}$ expression and reduced proinflammatory cytokine gene expression and apoptotic cell death in tumor necrosis factor a-stimulated proximal tubular cells. Taken together, we conclude that a7nAChR activation in proximal tubular cells directly protects cells against renal IR injury by inducing HO-1 expression through PI3K/Akt and PKC signaling.
\end{abstract}

\section{Introduction}

Acute kidney injury is associated with high rates of morbidity and mortality in hospitalized patients ${ }^{1}$. Ischemia-reperfusion (IR) injury is the most common cause of acute kidney injury and is a significant risk factor for chronic kidney disease in the elderly ${ }^{2}$. IR injury causes tubular and microvascular damage; initiates acute

\footnotetext{
Correspondence: Sang Won. Park (parksw@gnu.ac.kr)

'Department of Pharmacology, Institute of Health Sciences, Gyeongsang

National University School of Medicine, Jinju, Republic of Korea
}

These authors contributed equally: Hwajin Kim, So Ra Kim. inflammatory responses; and results in apoptotic or necrotic cell death, tissue damage, and renal dysfunction ${ }^{3}$.

Acetylcholine signals transduced through nicotinic receptors (ligand-gated ion channels) that are prominently expressed in macrophages inhibit proinflammatory cytokine synthesis ${ }^{4}$. The $\alpha 7$ nicotinic acetylcholine receptor $(\alpha 7 \mathrm{nAChR})$ is a critical regulator of cholinergic anti-inflammatory responses in several disease models of endotoxemic shock, sepsis, IR, colitis, and pancreatitis ${ }^{5,6}$. Nicotine, a selective cholinergic agonist that is more efficient than acetylcholine, inhibits tumor necrosis factor (TNF)-induced endothelial cell activation during 
endotoxin-induced inflammation by blocking nuclear factor- $\kappa B$ (NF- $\kappa B$ ) signaling ${ }^{7}$. In animal models of sepsis, nicotine attenuates the secretion of high-mobility group box 1 (HMGB1) from macrophages and improves survi$\mathrm{val}^{8}$. During IR injury, nicotine has an anti-inflammatory effect; ${ }^{9}$ however, the underlying molecular mechanisms remain unclear. Heme oxygenase-1 (HO-1) is a cytoprotective enzyme that catalyzes the degradation of heme to biliverdin, carbon monoxide, and free $\operatorname{iron}^{10}$. The induction of HO-1 downregulates proinflammatory cytokines and attenuates tissue damage during IR injury; however, little is known about the molecular mechanisms underlying $\alpha 7 \mathrm{nAChR}$ and HO-1 signaling in renal IR.

In this study, the $\alpha 7 n$ AChR agonist GTS-21 dihydrochloride (DMBX-A) and the antagonist methyllycaconitine (MLA) were used to investigate the effect of $\alpha 7 n A C h R$ activation on renal IR. We showed that $\alpha 7 \mathrm{nAChR}$ activation in proximal tubular cells protected the kidney against IR injury in vivo in mice and in vitro in proximal tubular cells. Here, we describe a molecular mechanism whereby $\alpha 7 \mathrm{nAChR}$ in proximal tubular cells protects the kidney from IR injury by increasing HO-1 expression levels via phosphoinositide 3-kinase (PI3K)/ Akt and protein kinase $\mathrm{C}(\mathrm{PKC})$ signaling.

\section{Materials and methods \\ Animals}

Male C57BL/6 mice (7 weeks old) were purchased from Koatech (Pyeongtaek, South Korea) and maintained in the animal facility at Gyeongsang National University (GNU). All animal experiments were approved by the Institutional Board of Animal Research at GNU and performed in accordance with the National Institutes of Health guidelines for laboratory animal care. The mice were housed with an alternating 12-h light/dark cycle and provided with water and standard chow ad libitum.

\section{Renal IR surgery}

The mice were divided into four groups: (1) shamoperated mice (Sham, $n=4$ ); (2) subjected to IR injury (Veh + IR, $n=8$ ); (3) IR mice pretreated for $1 \mathrm{~h}$ prior to IR injury with DMBX-A (Abcam, Cambridge, UK; $4 \mathrm{mg} /$ $\mathrm{kg}$, i.p.) (DMBX + IR, $n=8)$; and (4) IR mice pretreated with DMBX-A ( $4 \mathrm{mg} / \mathrm{kg}$ ) and MLA (Abcam; $3 \mathrm{mg} / \mathrm{kg}$, i.p.) $(\mathrm{MLA}+\mathrm{DMBX}+\mathrm{IR}, \quad n=8)$. The mice were intramuscularly anesthetized with zoletil $(0.5 \mathrm{mg} / \mathrm{kg}$; Virbac Laboratories, Carros, France) and placed supine on a heating pad under a heat lamp to maintain the body temperature at $37^{\circ} \mathrm{C}$. The kidneys were exposed via flank incisions. The right renal pedicle was ligated, and the left renal pedicle was clamped with a microaneurysm clip for $25 \mathrm{~min}$. After removal of the clip, the wounds were sutured, and the sham mice were subjected to right nephrectomy only without clamping. The mice were sacrificed 4 or $24 \mathrm{~h}$ after reperfusion. To assess renal function, plasma creatinine $(\mathrm{pCr})$ was measured by an enzymatic method using Pure Auto S CRE-N (Daiichi Sankyo, Tokyo, Japan). The kidneys were excised and either snap-frozen in liquid nitrogen for western blotting and quantitative PCR analyses or perfusion-fixed in $4 \%$ formalin for histologic studies.

\section{Cell culture and treatment}

HK-2 human proximal tubular epithelial cells were maintained in a 1:1 mixture of Dulbecco's modified Eagle's medium (Thermo Fisher Scientific, Waltham, MA, USA)/Kaighn's modification of Ham's F-12 medium (F-12K; Thermo Fisher Scientific) supplemented with 10\% fetal bovine serum and $1 \%$ penicillin/streptomycin (HyClone Laboratories, Logan, UT, USA). PKC $\alpha$-specific, PKB 31 -specific, and HO-1-specific small interfering RNA (siRNA) and control scrambled siRNA were purchased from Bioneer (Daejeon, South Korea). The cells were transfected using Lipofectamine (Invitrogen, Carlsbad, CA, USA) and incubated with siRNA for $24 \mathrm{~h}$. The siRNA-treated cells exhibited no cytotoxicity. Cells were then treated with DMBX-A (DMBX, Abcam, Cambridge, UK), MLA (Abcam), LY294002 (Sigma, St. Louis, MO, USA), wortmannin (Sigma), and Gö6983 (Sigma) as indicated in the figure legends. Cells were treated with recombinant TNF- $\alpha$ (R\&D Systems, Minneapolis, MN, USA) to stimulate the IR-induced cellular response.

\section{Cell viability}

Cell viability was determined by 3-(4,5-dimethyldiazol2-yl)-2,5-diphenyltetrazolium bromide (MTT) assay. After drug treatment, $200 \mu \mathrm{l}$ of MTT solution was added to each well (final $0.1 \mathrm{mg} / \mathrm{ml}$ ), and the cells were incubated for $4 \mathrm{~h}$ at $37^{\circ} \mathrm{C}$. The supernatant was aspirated, and formazan crystals were dissolved in $200 \mu \mathrm{l}$ of dimethyl sulfoxide. Absorbance at $570 \mathrm{~nm}$ was measured using an Infinite 200 microplate reader (Tecan Austria GmbH, Grödig, Austria).

\section{Tissue preparation and H\&E staining}

Mice were anesthetized and perfused with heparinized saline through the abdominal aorta; the kidneys were removed and fixed in $10 \%$ formalin for $24 \mathrm{~h}$. The kidneys were processed for paraffin embedding, and $5-\mu \mathrm{m}$ sections were prepared. The sections were stained with hematoxylin and eosin (H\&E) (Sigma), and images were captured using a CKX41 light microscope (Olympus, Tokyo, Japan). The extent of kidney injury was scored using the Jablonkski grading scale as previously described ${ }^{11}$.

\section{TUNEL assay}

Terminal deoxynucleotidyl transferase dUTP nick-end labeling (TUNEL) analysis was performed to measure 
(A)

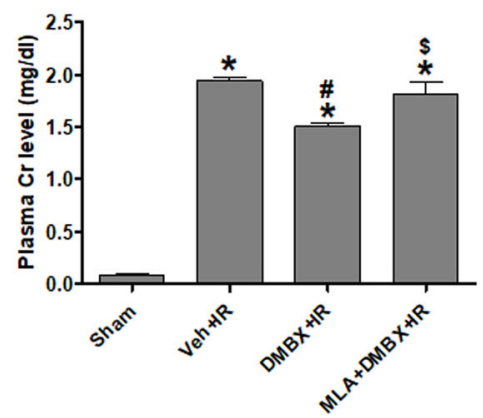

(B)
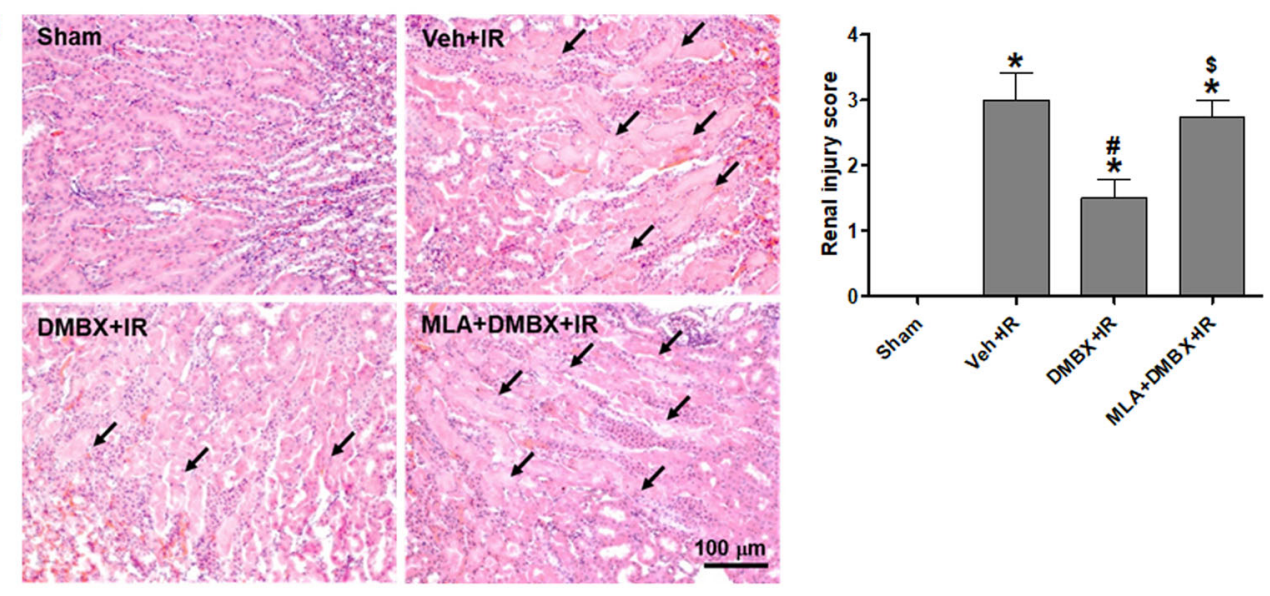

(C)
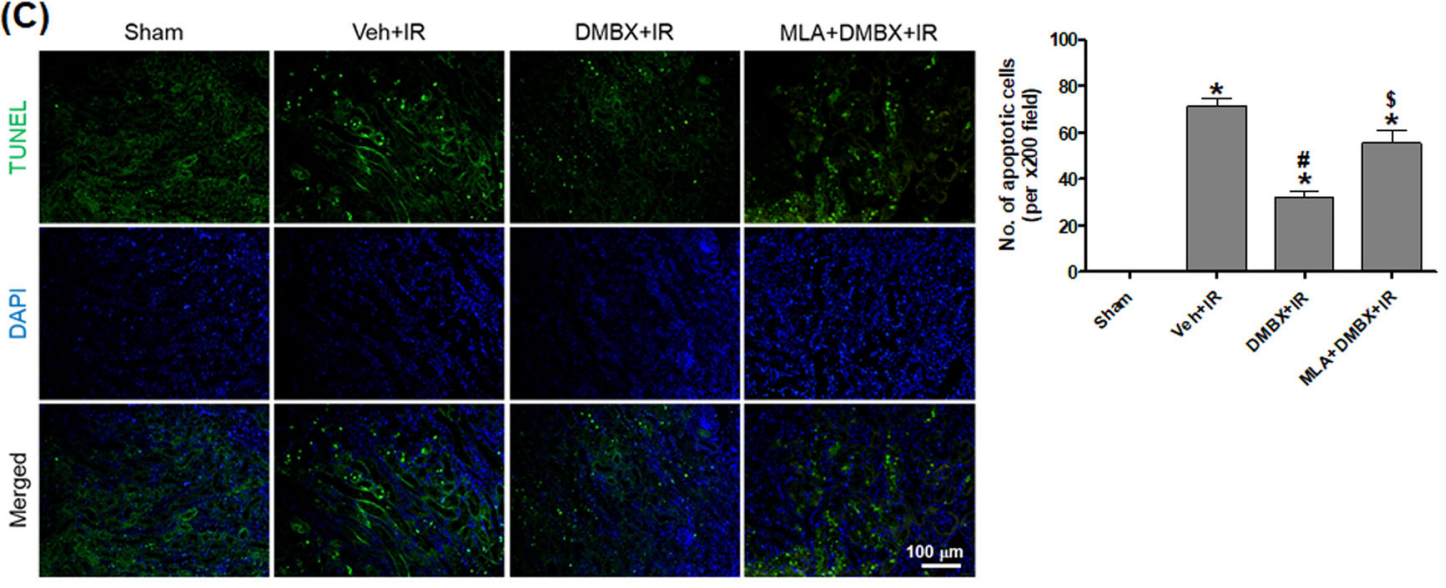

(D)
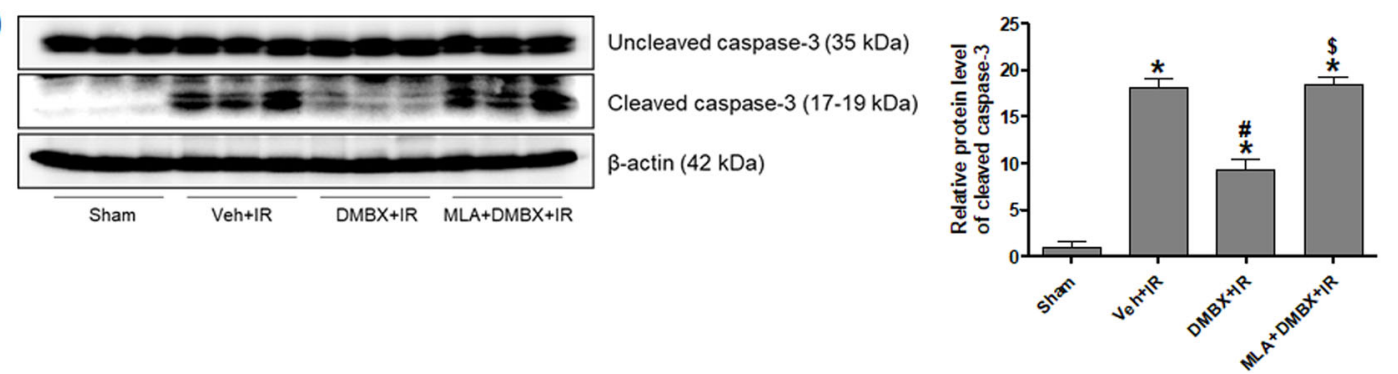

Fig. 1 (See legend on next page.) 
(see figure on previous page)

Fig. $1 \mathrm{a} 7 \mathrm{nAChR}$ activation attenuates renal injury after ischemia-reperfusion (IR). Blood samples and kidney tissues from sham mice, IR mice, and IR mice pretreated with DMBX or DMBX + MLA were collected at $24 \mathrm{~h}$ after reperfusion. a Plasma levels of the renal injury marker creatinine were measured. b Kidney tissues were processed for histologic staining with hematoxylin and eosin, and representative images are shown. Arrows indicate damaged tubules. The extent of kidney injury was scored using the Jablonkski grading scale as described. c Renal tubular cell death was analyzed by terminal deoxynucleotidyl transferase dUTP nick-end labeling (TUNEL), and the number of apoptotic cells per $\times 200$ field image was counted. $\mathbf{d}$ Protein expression levels of uncleaved and cleaved caspase-3 were determined by western blot in kidney lysates, and the quantitative analysis is shown. The data are presented as the mean \pm SEM. ${ }^{*} P<0.05$ vs. Sham, ${ }^{\sharp} P<0.05$ vs. Veh $+I R$, and ${ }^{\$} P<0.05$ vs. DMBX $+I R$. Scale bar, $100 \mu m$

the degree of apoptosis by using an in situ cell death detection kit (Roche Molecular Biochemicals, Mannheim, Germany) according to the manufacturer's protocol. Images were captured using a CKX41 light microscope (Olympus) and quantified by using Image (National Institutes of Health, Bethesda, MD, USA, http://imageJ. nih.gov/ij). The number of TUNEL-positive (apoptotic) cells were counted from THREE images of $\times 200$ microscopic fields per kidney section from each group.

\section{Immunohistochemistry}

Sections were blocked with 10\% normal horse serum and incubated with primary antibodies (anti-Ly-6B.2 from Bio-Rad and anti-HMGB1 from Abcam) overnight at $4{ }^{\circ} \mathrm{C}$. The sections were washed and incubated with biotinylated secondary antibody (Vector Laboratories, Burlingame, CA, USA) for $1 \mathrm{~h}$ at room temperature. The sections were washed again and incubated in an avidin-biotin-peroxidase complex solution (ABC solution; Vector Laboratories) and then developed using a 3,3'-diaminobenzidine peroxidase substrate kit (Vector Laboratories). The sections were counterstained with hematoxylin solution, and images were captured using a CKX41 light microscope (Olympus) and quantified by using ImageJ (NIH). The number of neutrophils was counted from three images of $\times 200$ microscopic fields per kidney section from each group.

\section{Immunofluorescence staining}

Sections were blocked with 2.5\% normal horse serum and incubated with primary antibodies (anti- $\alpha 7 n A C h R$ and anti-AQP1 from Santa Cruz Biotechnology; anti-calbindin from Abcam) overnight at $4{ }^{\circ} \mathrm{C}$. After washing, the sections were incubated with Alexa Fluor488-conjugated and/or Alexa Fluor594-conjugated secondary antibodies (Vector Laboratories). Fluorescence was visualized using a Fluoview 1000 (IX-81) confocal microscope (Olympus), and the images were quantified by using Image $(\mathrm{NIH})$.

\section{Western blot analysis}

Kidney tissues or HK-2 cells were homogenized in ice-cold radioimmunoprecipitation assay buffer with protease inhibitors (Thermo Fisher Scientific), sonicated, and incubated for $20 \mathrm{~min}$ on ice. After centrifugation, the supernatants were transferred to clean tubes, and the protein concentrations were determined using a Bio-Rad protein assay kit (Bio-Rad, Hercules, CA, USA). Nuclear and cytoplasmic protein fractions were isolated using an NE-PER Nuclear and Cytoplasmic Extraction Reagent kit (Thermo Fisher Scientific) according to the manufacturer's instructions. The protein samples were separated and transferred onto polyvinylidene fluoride membranes; the membranes were then incubated with primary antibodies against p-PKC (pan, $\alpha \beta I I), p-A k t$, Akt, caspase-3, and HO-1 (Cell Signaling Technology, Danvers, MA, USA); PKC, $\alpha 7 \mathrm{nAChR}$, and poly (ADPribose) polymerase 1 (PARP-1) (Santa Cruz Biotechnology); and p84 and HMGB1 (Abcam). Next, the membranes were incubated with horseradish peroxidaseconjugated secondary antibodies (Bio-Rad) and finally with ECL substrates (Bio-Rad). The ChemiDoc XRS + System (Bio-Rad) was used to analyze the protein band densities.

\section{Reverse transcription and quantitative PCR}

Total RNA was extracted using Trizol (Thermo Fisher Scientific) and converted into cDNA with the RevertAid Reverse Transcription System (Thermo Fisher Scientific) according to the manufacturer's protocol. Quantitative PCR was performed on a CFX Connect Real-Time PCR System using iQ SYBR Green Supermix (Bio-Rad). Relative mRNA levels were normalized to that of glyceraldehyde 3-phosphate dehydrogenase. The primers used were as follows (mouse, m; human, $h$ ): $\alpha 7 \mathrm{nAChR}(\mathrm{m})$ 5'-CATACCCAGATGTCACCTACAC-3' (forward); $\alpha 7 \mathrm{nAChR}(\mathrm{m}) \quad 5^{\prime}$-GCAGCAAGACCAGCAAAG-3' (reverse); HO-1(m) 5'-CTCCCTGTGTTTCCTTTCTCT C-3' (forward); HO-1(m) 5'-GCTGCTGGTTTCAAAGTTCAG-3' (reverse); interleukin-6 (IL-6)(m) 5'-CCAATTCATCTTGAAATCAC-3' (forward); IL-6(m) 5'-GGAATGTCCACAAACTGATA-3' (reverse); macrophage inflammatory protein-2 (MIP-2)(m) 5'-AGAG GGTGA-GTTGGGAACTA-3' (forward); MIP-2(m) 5'GCCATCCGACTGCATCTATT-3' (reverse); TNF $\alpha(\mathrm{m})$ 5'-CATATACCTGGGAGGAGTCT-3' (forward); TNF $\alpha$ (m) 5'-GAGCAATGA CTCCAAAGTAG-3' (reverse); $\alpha 7 \mathrm{nAChR}(\mathrm{h}) \quad 5^{\prime}$-GACGCCACATTCCACACTAA-3' 


\section{(A)}
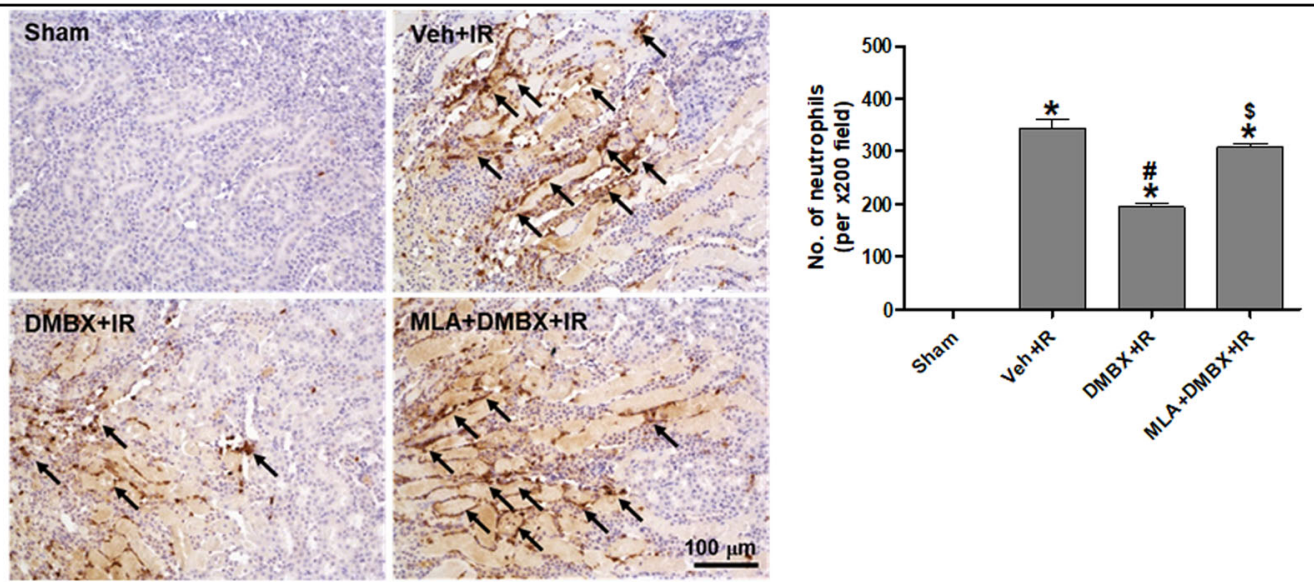

(B)
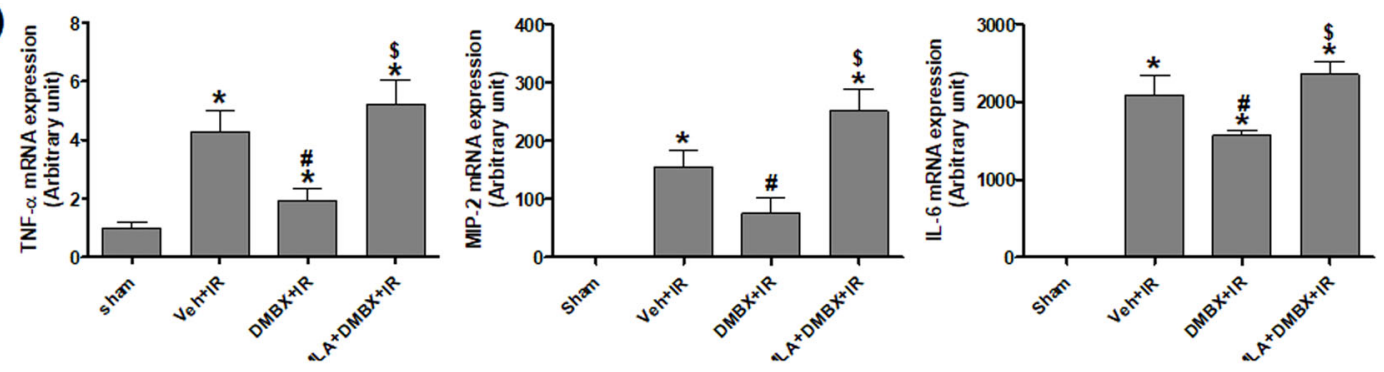

(C)
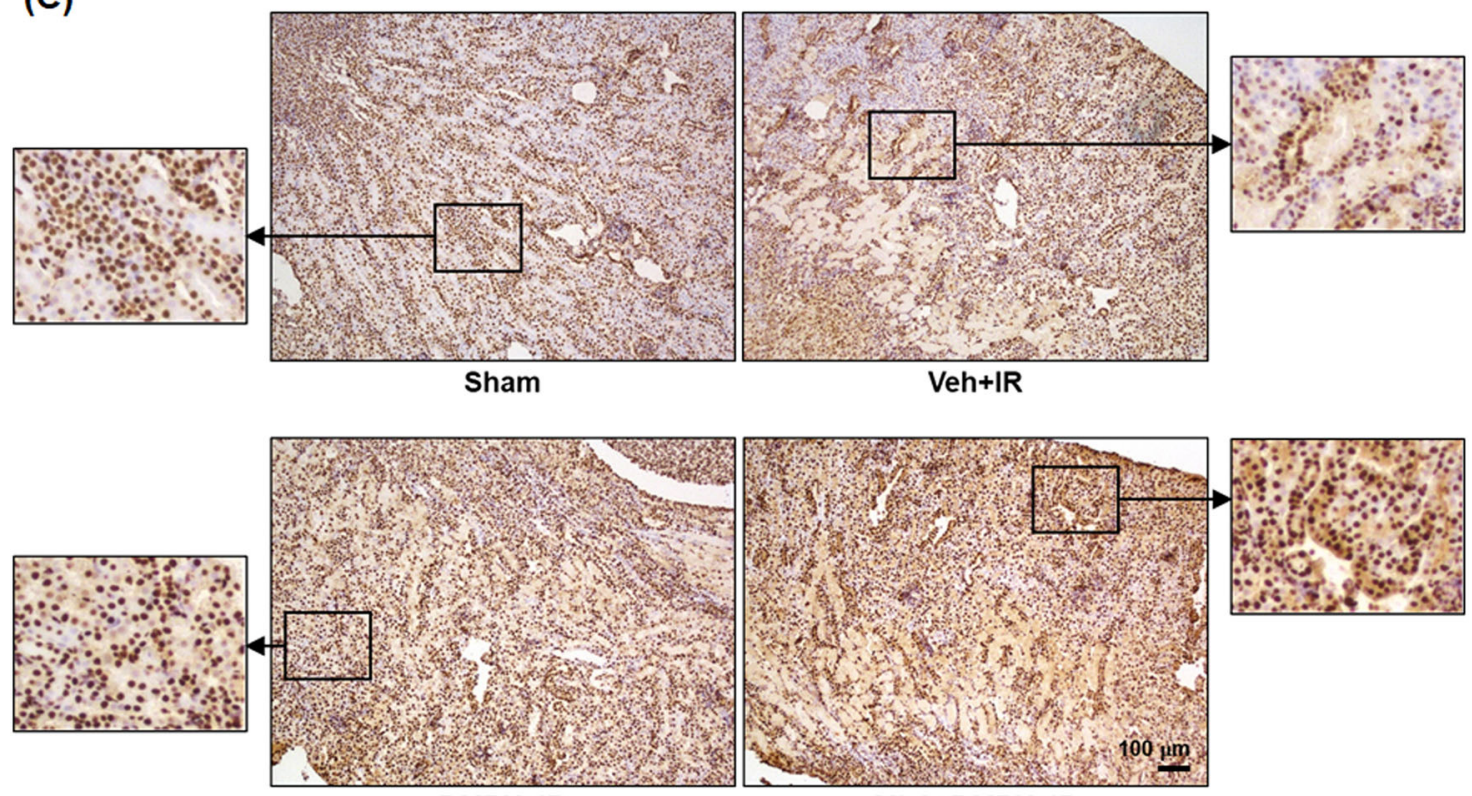

DMBX+IR
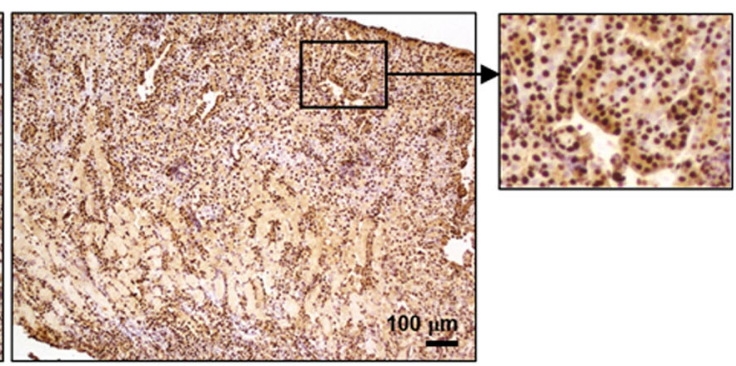

Fig. 2 a7nAChR activation attenuates renal inflammation and HMGB1 release after IR. Kidney tissues from sham mice, IR mice, and IR mice pretreated with DMBX or DMBX + MLA were collected at $4 \mathrm{~h}$ for mRNA extraction or $24 \mathrm{~h}$ for immunostaining and western blot analyses after reperfusion. a Neutrophil infiltration was assessed by polymorphonuclear leukocyte (anti-Ly-6B.2) staining, and the number of stained neutrophils per $\times 200$ field image was counted. Arrows indicate Ly-6B.2-positive cells. b Relative mRNA expression levels of macrophage inflammatory protein-2 (MIP2), interleukin-6 (IL-6), and tumor necrosis factor-a (TNF-a) were determined by real-time PCR analysis. c Localization of the HMGB1 protein in renal tubular cells was analyzed by immunohistochemical staining. Higher magnification images of the proximal tubular cells are shown to indicate the predominantly nuclear HMGB1 expression in sham and DMBX + IR mice and the increased cytosolic HMGB1 expression in Veh + IR and MLA + DMBX + IR mice. $\mathbf{d}$ Nuclear and cytosolic fractionation of kidney lysates was performed to determine the nuclear-to-cytosolic translocation of the HMGB1 protein. The expression levels of HMGB1, the nuclear marker p84, and the cytosolic marker a-tubulin were determined in each fraction; the quantitative analysis is shown. The data are presented as the mean \pm SEM. ${ }^{*} P<0.05$ vs. Sham, ${ }^{\#} P<0.05$ vs. Veh $+I R$, and ${ }^{\$} P<0.05$ vs. DMBX $+I R$. Scale bar, $100 \mu m$ 
(D) Cytosolic fraction
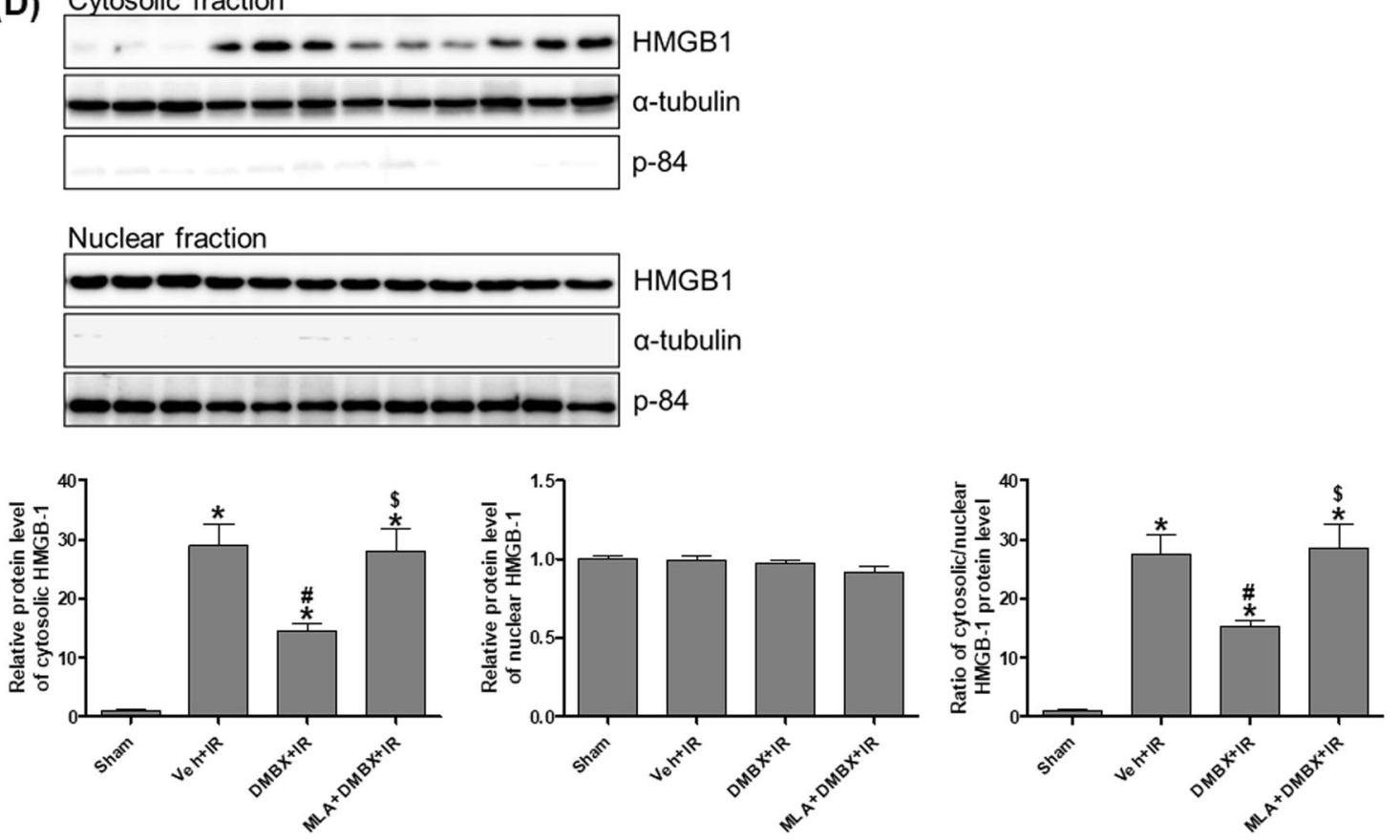

Fig. 2 Continued.

(forward); $\quad \alpha 7 \mathrm{nAChR(h)} \mathrm{5'-AAGGGAAACCAGCG-TA}$ CATC-3' (reverse); HO-1(h) 5'-TCAGGCAGAGGG TGATAGAA-3' (forward); HO-1(h) 5'-GCTCCTGC-A ACTCCTCAAA-3' (reverse); MIP-2(h) 5'-GCATCGCCC ATGGTTA-AGA-3' (forward); MIP-2(h) 5'-TCAGGAA CAGCCACCAATAAG-3' (reverse); IL-6(h) 5'-CCAGG AGAAG-ATTCCAAAGATGTA-3' (forward); IL-6(h) 5' CGTCGAGGATGTACC-GAATTT-3' (reverse); IL-10(h) 5' -TTTCCCTGACCTCCCTCTAA-3' (forward); IL-10(h) 5'-CGAGACACTGG-AAGGTGAATTA-3' (reverse); MCP-1(h) 5'-GGCTGAGACTAACCC-AGAAAC-3' (forward); MCP-1(h) 5'-GAATGAAGGTGGCTGCTAT GA-3' (reverse); TNF $\alpha(\mathrm{h})$ 5'-TGCTGCAGGACTTGAG AAGA-3' (forward); and TNF $\alpha(\mathrm{h}) 5^{\prime}$-GGCTACATGG-G AACAGCCTA-3' (reverse).

\section{Statistical analysis}

Statistical differences among the groups were determined with one-way analysis of variance, followed by Bonferroni post hoc analysis. The values are expressed as the mean \pm SEM. $P$ values $<0.05$ were considered statistically significant.

\section{Results}

a7nAChR activation decreases renal injury and tubular cell death in IR mice

To determine the effect of $\alpha 7 \mathrm{nAChR}$ activation on renal IR injury, mice were treated with an $\alpha 7 n A C h R$ agonist, DMBX-A, before IR injury. We examined renal dysfunction by measuring plasma creatinine $(\mathrm{Cr})$ levels (Fig. 1a).
Mice subjected to IR injury (IR mice) had significantly increased $\mathrm{Cr}$ levels, which were inhibited by DMBX-A pretreatment; this effect was blocked by co-treatment with MLA, an $\alpha 7 \mathrm{nAChR}$ antagonist. In addition to measuring $\mathrm{Cr}$ levels, we examined renal histological changes by $H \& E$ staining (Fig. 1b). IR mice showed significant tubular necrosis and proteinaceous casts with increased congestion. Consistent with the $\mathrm{Cr}$ levels, DMBX-A treatment reduced renal necrosis and tubular injury, and these effects were blocked by co-treatment with MLA.

To determine the effect of $\alpha 7 \mathrm{nAChR}$ activation on IRinduced tubular cell death, we performed TUNEL assays (Fig. 1c). Compared to sham mice, IR mice showed a dramatic increase in TUNEL-positive cells. DMBX-A decreased this IR-induced cell death, and this effect was blocked by MLA. We examined the kidney levels of cleaved caspase-3 (Fig. 1d) and found that the increase in IR mice was attenuated by DMBX-A; this effect was blocked by MLA. Taken together, the plasma Cr levels, histological staining for tubule damage, TUNEL staining, and renal apoptotic protein levels all indicated that $\alpha 7 \mathrm{nAChR}$ activation reduced tubular damage and preserved tissue integrity after IR; thus, $\alpha 7 \mathrm{nAChR}$ activation may protect the kidneys from functional failure after IR.

\section{a7nAChR activation attenuates renal inflammation and HMGB1 release in IR mice}

To determine the effect of $\alpha 7 \mathrm{nAChR}$ activation on inflammation, we first examined neutrophil infiltration 24 $\mathrm{h}$ after IR (Fig. 2a). DMBX-A reduced neutrophil 
infiltration, and this effect was blocked by co-treatment with MLA. We then analyzed the renal expression levels of TNF- $\alpha$, MIP-2, and IL-6 mRNA $4 \mathrm{~h}$ after IR (Fig. 2b). Consistent with the polymorphonuclear leukocyte staining results, IR mice exhibited increases in TNF- $\alpha$, MIP-2, and IL-6 mRNA levels. These levels decreased with DMBX-A treatment, and this effect was blocked by MLA.

To determine the effect of $\alpha 7 \mathrm{nAChR}$ activation on IR-induced HMGB1 release, we examined HMGB1 expression by immunohistochemical staining (Fig. 2c). HMGB1 was predominantly located in the nucleus in sham-operated mice; however, nuclear HMGB1 was dramatically reduced, and cytoplasmic HMGB1 was increased in IR mice. These effects were attenuated by DMBX-A, and the effects of DMBX-A were blocked by MLA. In addition, we isolated nuclear and cytosolic proteins to determine the nuclear-to-cytoplasmic translocation of the HMGB1 protein by western blotting (Fig. 2d). Cytoplasmic HMGB1 levels were increased by IR and attenuated by DMBX-A treatment; the effects of DMBXA were blocked by MLA. These results indicate that $\alpha 7 \mathrm{nAChR}$ activation reduced IR-induced

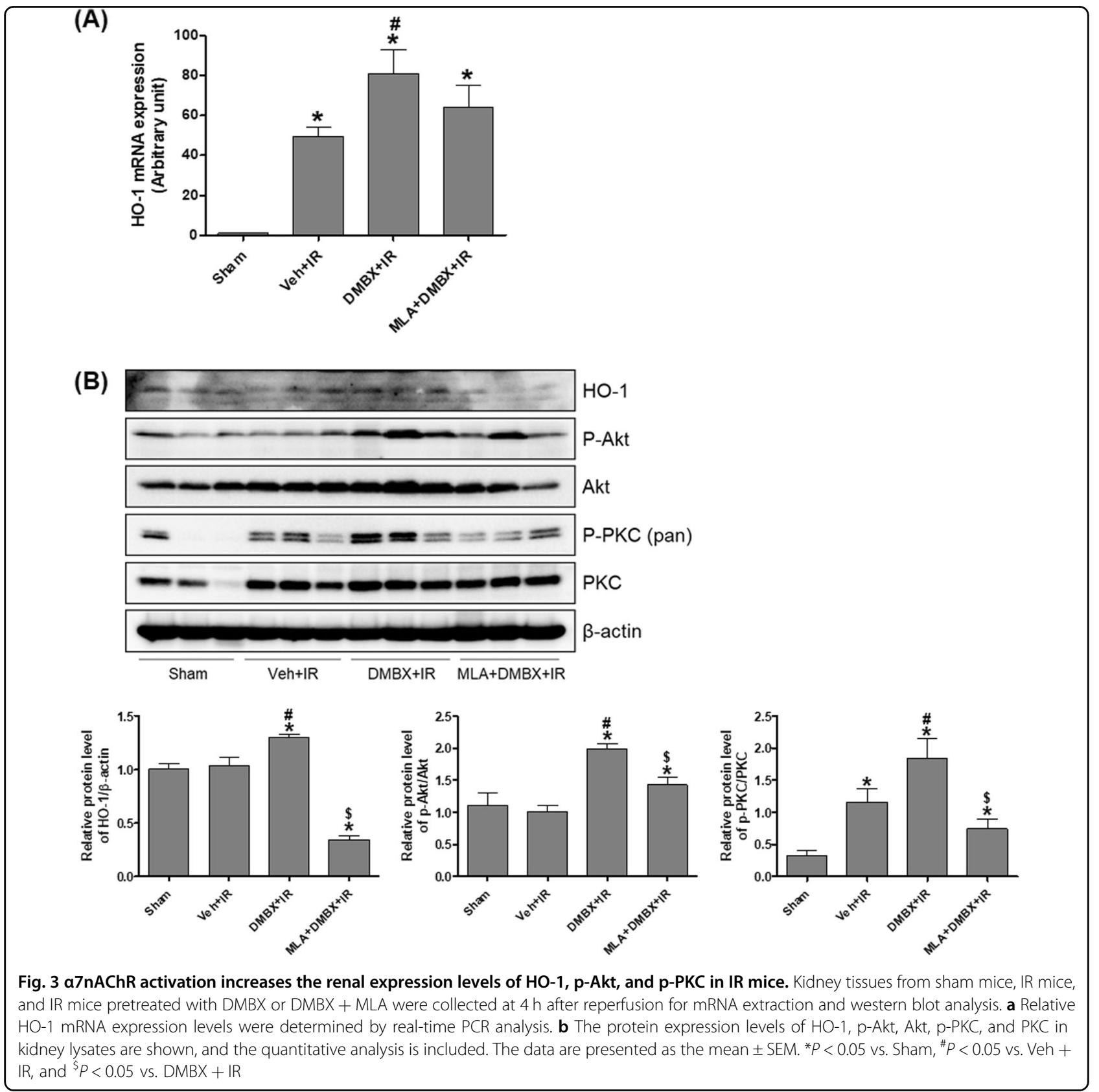


proinflammatory responses and the release of nuclear HMGB1 protein, a critical mediator of inflammation.

\section{a7nAChR activation increases HO-1, p-Akt, and p-PKC} expression levels in IR mice

We investigated whether $\alpha 7 \mathrm{nAChR}$ activation increases HO-1 expression levels, which involves PKC and PI3K/ Akt signaling. The renal expression of HO-1 mRNA was increased $4 \mathrm{~h}$ after IR and was further enhanced by DMBX-A; the DMBX-A effect was blocked by MLA (Fig. 3a). We then analyzed the renal protein levels of HO-
1, p-Akt, and p-PKC (pan) $4 \mathrm{~h}$ after IR, as well as the effects of DMBX-A and MLA treatment (Fig. 3b). Compared to sham mice, IR mice had a significant increase in HO-1 levels after DMBX-A treatment, and this effect was blocked by MLA. Similarly, p-Akt and p-PKC levels were increased by DMBX-A treatment in IR mice, and these effects were blocked by MLA.

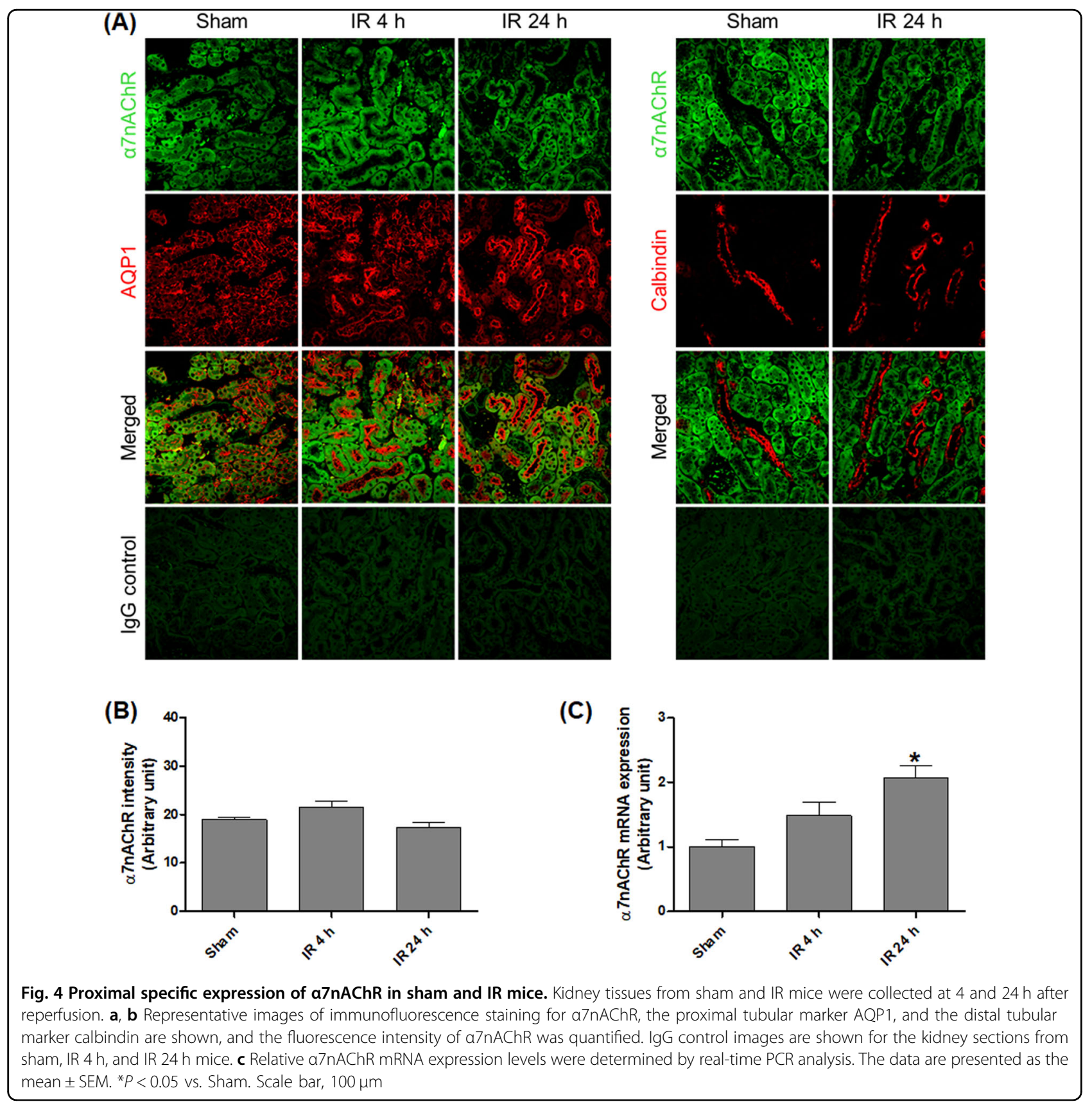


a7nAChR activation increases HO-1 expression and decreases inflammatory cytokine expression in proximal tubular cells

To examine the cellular localization of $\alpha 7 \mathrm{nAChR}$, kidney sections were stained with an $\alpha 7 \mathrm{nAChR}$ antibody along with an antibody against AQP1, a proximal tubule marker, or an antibody against calbindin, a distal tubule marker. In sham and IR mice, $\alpha 7 \mathrm{nAChR}$ was expressed in proximal tubular cells, but not in distal tubular cells (Fig. 4a). $\alpha 7 \mathrm{nAChR}$ protein expression levels were not significantly different in sham and IR mice at 4 or $24 \mathrm{~h}$ after reperfusion as shown by $\alpha 7 \mathrm{nAChR}$ immunofluorescence staining (Fig. 4b). However, we found a 2 -fold increase in renal $\alpha 7 \mathrm{nAChR}$ mRNA levels in IR mice compared to sham mice at $24 \mathrm{~h}$ after reperfusion (Fig. 4c). The upregulation of $\alpha 7 \mathrm{nAChR}$ mRNA may be protective, but the exact mechanism has not been determined.

To study the molecular mechanism of $\alpha 7 \mathrm{nAChR}$ activation in proximal tubular cells, HK-2 cells were used. First, we determined the concentrations of DMBX-A and MLA with minimal toxicity by MTT assay (Fig. 5a). MLA and DMBX-A showed no cellular toxicity at concentrations up to $25 \mu \mathrm{M}$; however, DMBX-A caused a significant decrease in cell viability at $50 \mu \mathrm{M}$. Thus, we treated cells with MLA and DMBX-A at $25 \mu \mathrm{M}$ in subsequent experiments. To determine the effect of $\alpha 7 \mathrm{nAChR}$ activation on HO-1 expression in HK-2 cells, we treated the cells with DMBX-A $(25 \mu \mathrm{M})$ for various times $(1-24 \mathrm{~h})$ or with various concentrations of DMBX-A $(1-25 \mu \mathrm{M})$ for $24 \mathrm{~h}$ (Fig. 5b, c). The results showed that DMBX-A significantly increased $\mathrm{HO}-1$ expression in a time-dependent and dose-dependent manner and that MLA co-treatment attenuated the DMBX-A-mediated induction of HO-1 (Fig. 5d).

To determine the effect of $\alpha 7 \mathrm{nAChR}$ activation on inflammatory cytokine expression in TNF- $\alpha$-stimulated cells, cells were pretreated with DMBX-A $(1,10$, or 25 $\mu \mathrm{M})$. The renal mRNA expression levels of proinflammatory cytokines (IL-6, MCP-1, and MIP-2) and an anti-inflammatory cytokine (IL-10) were analyzed (Fig. 5e). The results showed that DMBX-A treatment reduced IL-6, MCP-1, and MIP-2 levels and increased IL10 levels in a dose-dependent manner. These data suggest that $\alpha 7 \mathrm{nAChR}$ activation increases anti-inflammatory HO-1 expression and attenuates proinflammatory responses in TNF- $\alpha$-stimulated proximal tubular cells.

In addition, we performed experiments to determine the effect of $\alpha 7 n A C h R$ activation in hypoxic HK-2 cells (Supplementary Fig. 1). The TNF- $\alpha$ mRNA levels were increased in hypoxic cells compared to those in normoxic cells. DMBX-A pretreatment reduced hypoxia-induced TNF- $\alpha$ expression. The HO- 1 mRNA levels were increased in hypoxic cells compared to those in normoxic cells; DMBX-A pretreatment further increased these levels. However, $\alpha 7 \mathrm{nAChR}$ mRNA levels were not different among all groups. These data indicate that $\alpha 7 \mathrm{nAChR}$ activation protects proximal tubular cells from hypoxic and/or TNF- $\alpha$-stimulated stress through inducing $\mathrm{HO}-1$ expression and limiting the inflammatory response.

\section{a7nAChR activation increases HO-1 expression through PKC activation and PI3K/Akt signaling in proximal tubular cells}

To determine whether the HO-1 expression induced by $\alpha 7 \mathrm{nAChR}$ activation is mediated by PI3K/Akt and PKC signaling, we utilized chemical inhibitors of PI3K/Akt and PKC and siRNA targeting PKC (siPKC $\alpha)$. We found that the levels of p-Akt and p-PKC (pan or $\alpha \beta I I$ ) increased at 5-10 min of DMBX-A treatment, decreased gradually, and finally reached the level of untreated cells after $60 \mathrm{~min}$ of DMBX-A treatment (Fig. 6a). When the cells were treated with the PI3K/Akt inhibitor LY294002 and wortmannin before DMBX-A treatment, DMBX-A-induced HO-1 upregulation was suppressed significantly (Fig. 6b). In addition, a pan-PKC inhibitor, Gö6983, significantly attenuated the DMBX-A-induced HO-1 upregulation (Fig. 6c). These results indicate that HO-1 upregulation induced by $\alpha 7 \mathrm{nAChR}$ activation is mediated directly by PI3K/Akt and PKC signaling in proximal tubular cells.

To determine which PKC isoforms regulate $\mathrm{HO}-1$, we transfected cells with siPKC $\alpha$ or siRNA targeting PKC $\beta I$ (siPKC $\beta \mathrm{I}$ ) and analyzed the HO-1 levels. Transfection with siPKC $\alpha$ led to a significant reduction in HO-1 levels; however, transfection with siPKC $\beta$ I showed no change. These results suggest that DMBX-A-induced $\mathrm{HO}-1$ expression was mediated by PKC $\alpha$ but not PKC $\beta I$ (Fig. 6d) and that PKC $\alpha$ plays a prominent role in $\alpha 7 \mathrm{nAChR}$-mediated $\mathrm{HO}-1$ induction.

To determine whether the PI3K/Akt and PKC pathway regulate each other's activity, the PI3K/Akt inhibitors LY294002 and wortmannin were used for pretreatment, and $\operatorname{siPKC}(\alpha$ or $\beta \mathrm{I})$ was transfected before DMBX-A treatment; then, p-PKC (pan or $\alpha \beta I I$ ) and p-Akt levels were analyzed (Fig. 6e, f). Interestingly, the PI3K/Akt inhibitors decreased the levels of p-PKC as well as p-Akt; however, siPKC decreased the levels of only p-PKC, but not $\mathrm{p}$-Akt. These data suggest that $\alpha 7 \mathrm{nAChR}$ activation increased PI3K/Akt activity upstream and that PKC signaling is downstream.

\section{a7nAChR activation decreases TNF-a-stimulated HMGB1 release through inducing $\mathrm{HO}-1$ in proximal tubular cells}

Cytokines, such as TNF- $\alpha$ and IL-6, play a major role in renal dysfunction in IR injury ${ }^{12}$.Therefore, HK-2 cells were treated with TNF- $\alpha(20 \mathrm{ng} / \mathrm{ml})$ to stimulate an IR-induced proximal tubular cellular response. To determine the effect of $\alpha 7 \mathrm{nAChR}$ activation on HMGB1 release 

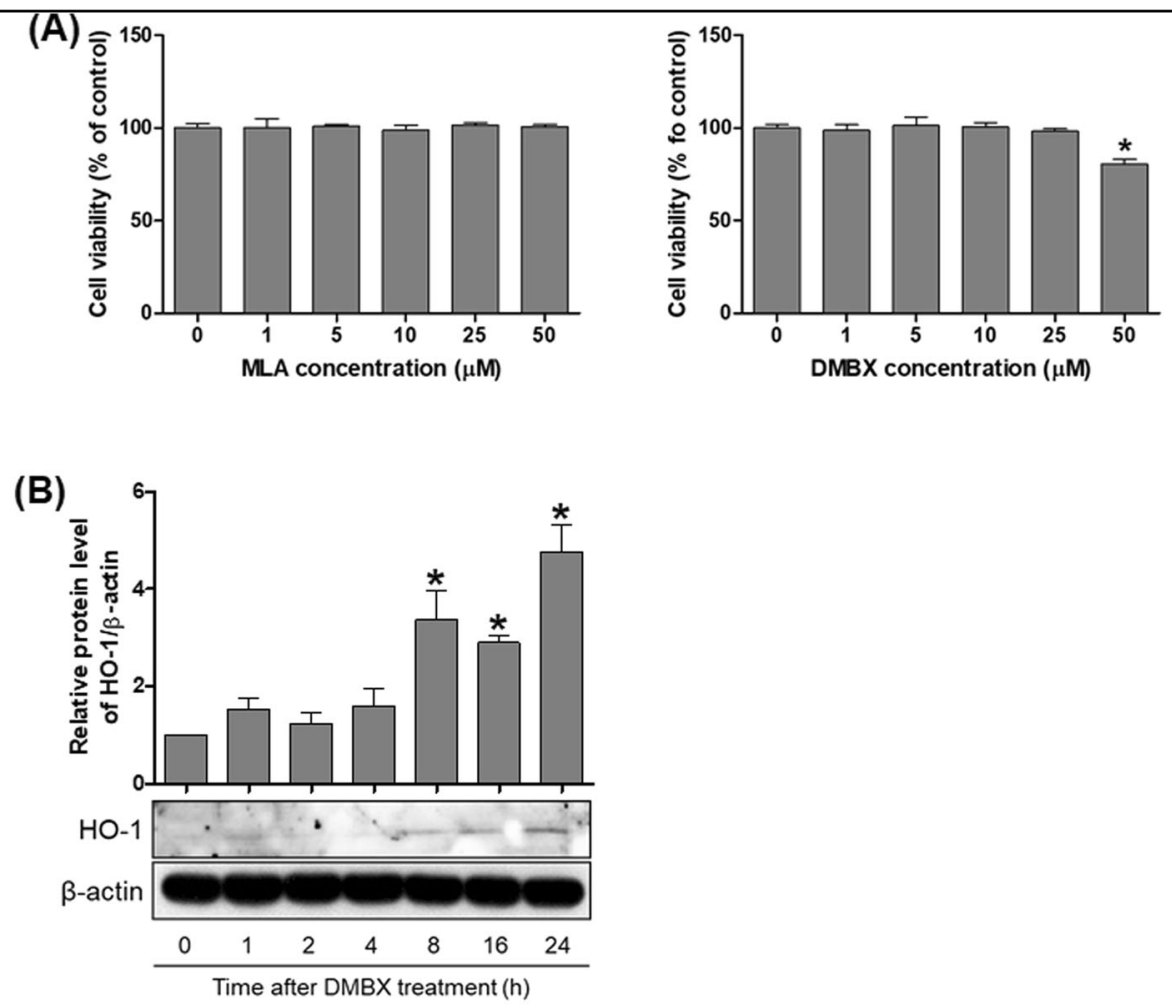

(C)
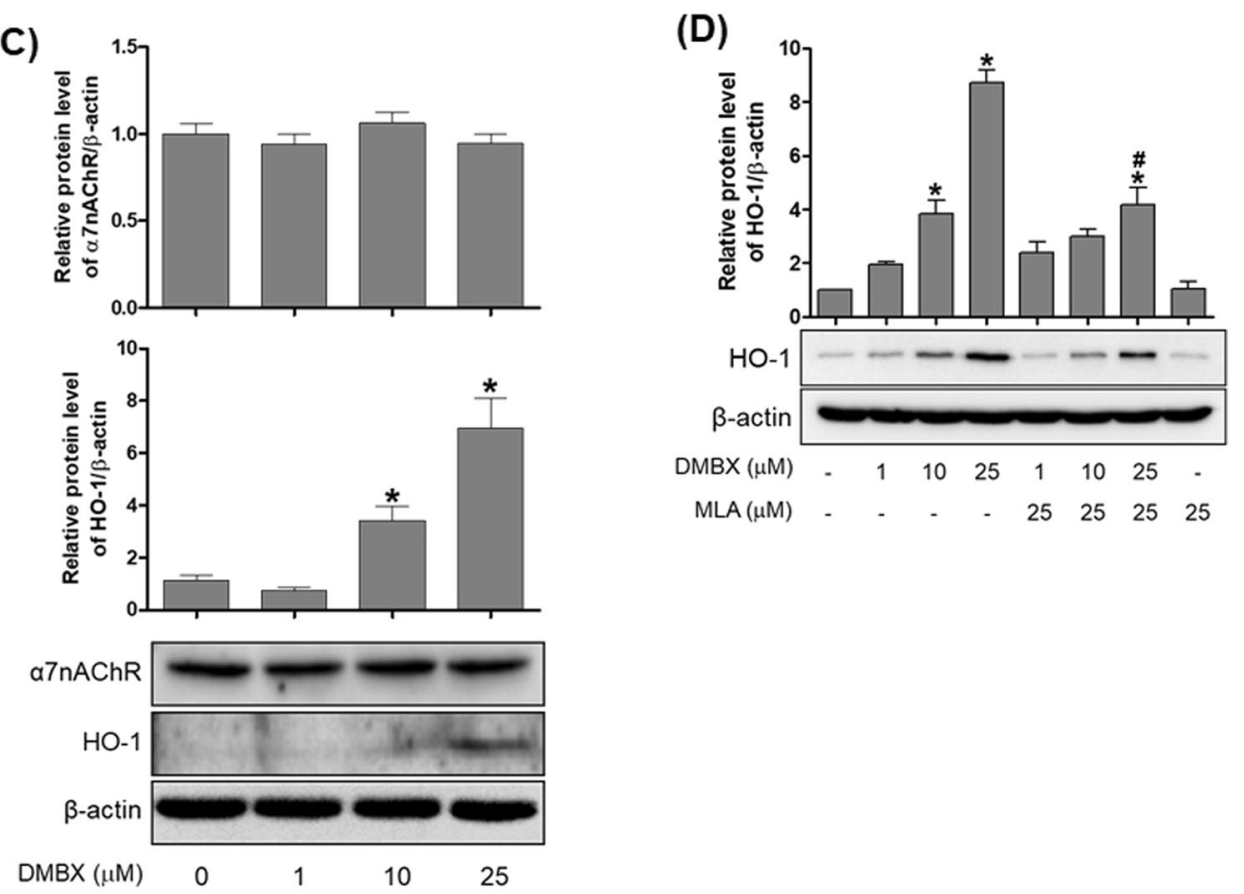

Fig. 5 a7nAChR activation increases HO-1 expression and decreases inflammatory cytokine levels in HK-2 human proximal tubule epithelial cells. a Cellular toxicity of MLA and DMBX-A; cells were treated with MLA or DMBX-A at concentrations of $0,1,5,10,25$, or $50 \mu \mathrm{M}$ for $24 \mathrm{~h}$, and cell viability was determined by MTT assay. ${ }^{*} P<0.05$ vs. untreated cells. $\mathbf{b}, \mathbf{c}$ Cells were treated with DMBX-A $(25 \mu \mathrm{M})$ for various times $(1-24 \mathrm{~h})$ or treated with DMBX-A $(1,10$, or $25 \mu \mathrm{M})$ for $24 \mathrm{~h}$. Then, the protein expression levels of HO-1 and a7nAChR were analyzed by western blot, and the quantification is shown. $\mathbf{d}$ Cells were pretreated with MLA $(25 \mu \mathrm{M})$ and DMBX-A $(1,10$, or $25 \mu \mathrm{M})$ for $24 \mathrm{~h}$. Then, HO-1 protein expression levels were analyzed by western blot. * $P<0.05$ vs. untreated cells, ${ }^{\#} P<0.05$ vs. DMBX-A-treated cells. e Cells were pretreated with DMBX-A (1, 10, or $\left.25 \mu \mathrm{M}\right)$ for $1 \mathrm{~h}$ and stimulated with TNF-a (10 ng/ml) for 2 h. Then, the relative mRNA expression levels of the proinflammatory cytokines IL-6, monocyte chemoattractant protein-1 (MCP-1), and MIP-2 and the antiinflammatory cytokine interleukin-10 (IL-10) were determined by real-time PCR analysis. ${ }^{*} P<0.05$ vs. untreated control cells, ${ }^{\#} P<0.05$ vs. TNF-a-stimulated cells 

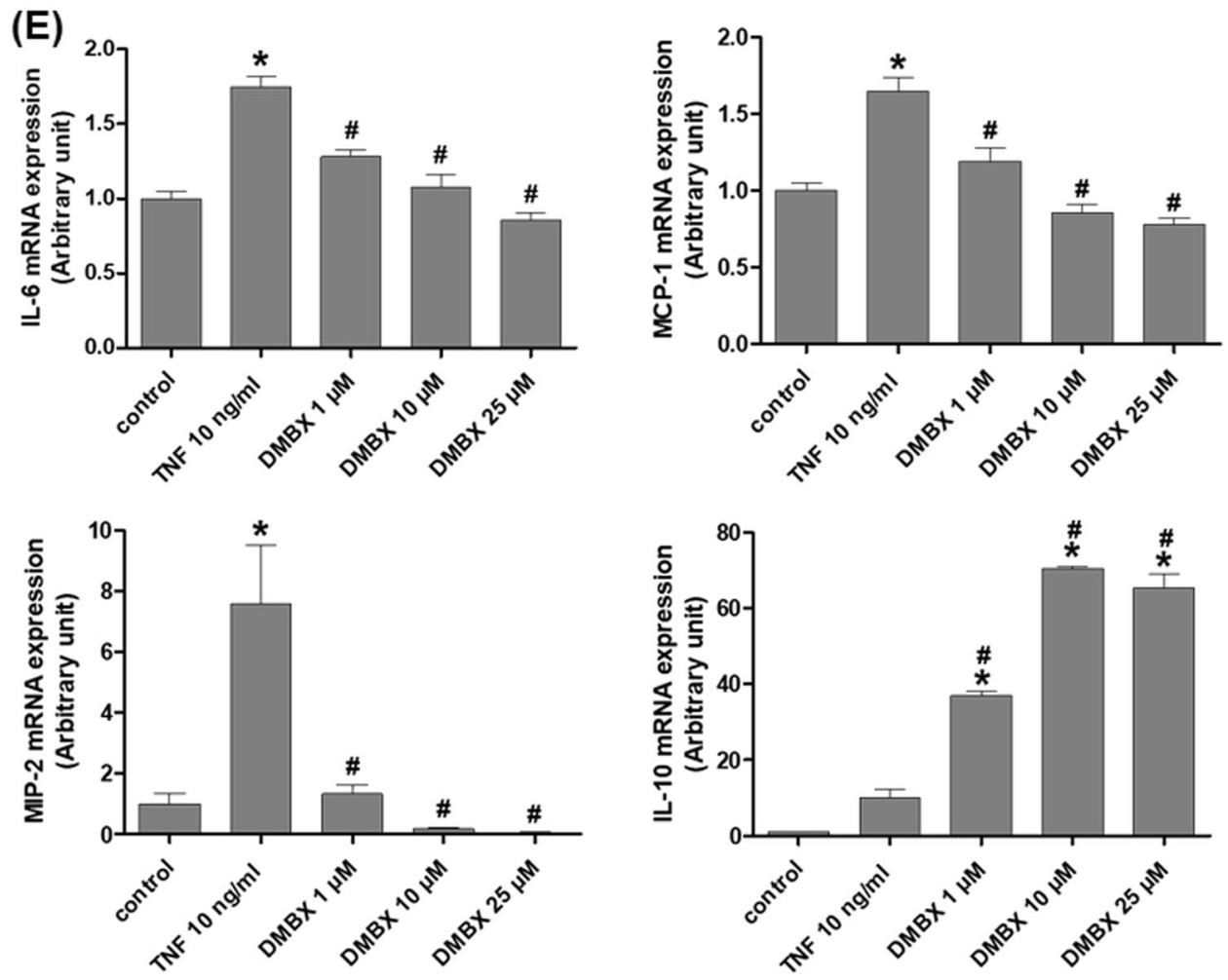

Fig. 5 Continued.

in TNF- $\alpha$-stimulated cells, cells were pretreated with DMBX-A and MLA, and HMGB1 release into the medium was analyzed. The results showed that DMBX-A significantly decreased HMGB1 release in TNF- $\alpha-$ stimulated cells, and this effect was blocked by MLA (Fig. 7a, b). We then investigated whether the $\alpha 7 \mathrm{nAChR}$ mediated reduction in HMGB1 release was blocked by HO-1 silencing. We first confirmed a significant decrease in HO-1 levels after transfection with siRNA targeting HO-1 (siHO-1) (Fig. 7c). The DMBX-A-induced reduction in HMGB1 release was blocked by siHO-1, but not by scrambled siRNA (Fig. 7d). These data suggest that HO-1 expression is critical for the $\alpha 7 \mathrm{nAChR}$-mediated reduction in HMGB1 release in TNF- $\alpha$-stimulated renal proximal tubular cells.

\section{a7nAChR activation decreases the TNF- $a$-stimulated activation of caspase- 3 and PARP-1 through PI3K/Akt signaling in proximal tubular cells}

To determine the effect of $\alpha 7 \mathrm{nAChR}$ activation on apoptosis in TNF- $\alpha$-stimulated cells, we pretreated cells with DMBX-A and assessed caspase-3 and PARP-1 activation by western blotting. Apoptotic cell death was induced by treatment with TNF- $\alpha(10 \mathrm{ng} / \mathrm{ml})$ and cycloheximide $(\mathrm{CHX}, 5 \mu \mathrm{M})$ for $2,4,6$, or $8 \mathrm{~h}$ (Fig. 8a). Caspase- 3 and PARP- 1 cleavage occurred at $4 \mathrm{~h}$ and was dramatically increased at $8 \mathrm{~h}$; the levels of cleavage were reduced by DMBX-A treatment. To determine whether the reduction in apoptosis by $\alpha 7 \mathrm{nAChR}$ activation was mediated by PI3K/Akt signaling, we treated cells with LY294002 and wortmannin before DMBX-A treatment and analyzed the levels of cleaved caspase- 3 and PARP-1 in cells stimulated with TNF- $\alpha$ and CHX for $8 \mathrm{~h}$ (Fig. 8b). LY294002 and wortmannin blocked the DMBX-Amediated reduction in caspase-3 and PARP-1 cleavage. These findings suggest that $\alpha 7 \mathrm{nAChR}$ activation attenuates apoptotic cell death through PI3K/Akt signaling in TNF- $\alpha$-stimulated proximal tubular cells.

\section{Discussion}

In this study, we demonstrated for the first time that proximal tubular $\alpha 7 \mathrm{nAChR}$ activation protected against ischemic acute kidney injury by attenuating renal inflammation and tubular cell death through PI3K/Akt and PKC signaling-mediated HO-1 induction. IR mice pretreated with DMBX-A exhibited significant decreases in $\mathrm{pCr}$ levels, tubular cell death, and proinflammatory cytokine levels and experienced $\mathrm{HO}-1$ induction. Furthermore, we revealed that $\alpha 7 \mathrm{nAChR}$ activation induced HO-1 through PI3K/Akt and PKC signaling in HK-2 cells. HO-1 upregulation inhibited HMGB1 release and provided protection against the inflammatory response and tubular cell death induced by IR injury. Importantly, the current study supports the idea that $\alpha 7 \mathrm{nAChR}$ activation 

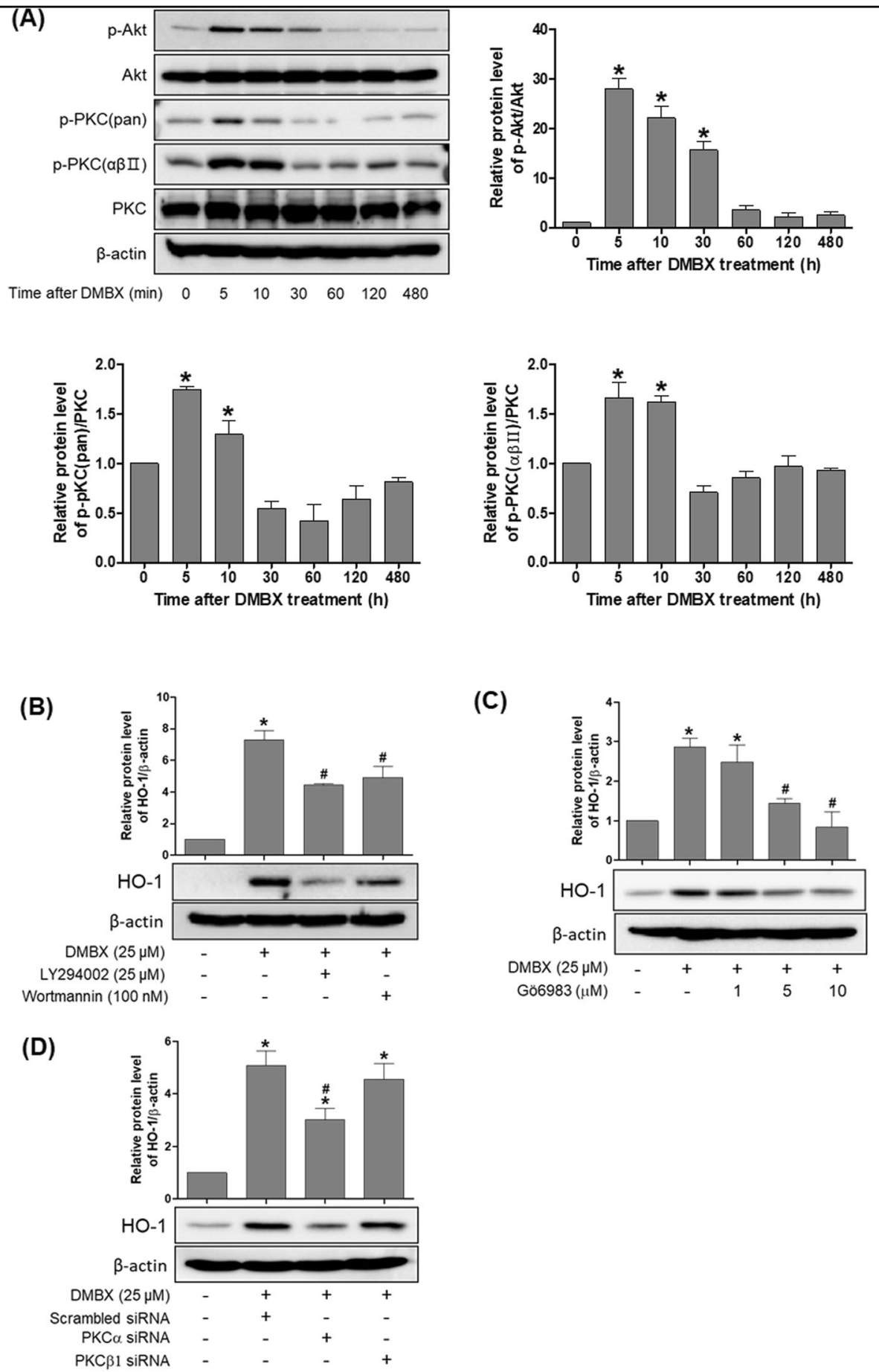

Fig. 6 a7nAChR activation increases HO-1 expression through the PKC and PI3K/Akt signaling pathway in HK-2 cells. a Cells were treated with DMBX-A $(25 \mu \mathrm{M})$ and collected at various times $(5,10,30,60,120$, and $480 \mathrm{~min})$ to prepare cell lysates. Then, the protein expression levels of $\mathrm{p}-$ Akt, Akt, p-PKC (pan, aßll), and PKC were determined by western blot, and the quantitative analysis is shown. $\mathbf{b}$, c Cells were pretreated for $1 \mathrm{~h}$ with LY294002 $(25 \mu \mathrm{M})$, wortmannin $(100 \mathrm{nM})$, or Gö6983 (1, 5, or $10 \mu \mathrm{M})$ and then treated with DMBX-A (25 $\mu \mathrm{M})$ for 24 h; next, HO-1 protein expression levels were analyzed. $\mathbf{d}$ Cells were transfected with scrambled siRNA or siRNA specific for PKCa or PKC $3 \|$ for $24 \mathrm{~h}$ and then treated with DMBX-A for $24 \mathrm{~h}$; next, HO-1 protein expression levels were analyzed. e Cells were pretreated with LY294002 $(25 \mu \mathrm{M})$ or wortmannin $(100 \mathrm{nM})$ for $1 \mathrm{~h}$ and then treated with DMBX-A $(25 \mu \mathrm{M})$ for $5 \mathrm{~min}$; next, the protein expression levels of $\mathrm{p}$-PKC, $\mathrm{p}$-Akt, and Akt were analyzed. $\mathbf{f}$ Cells were transfected with siPKCa, siPKC $B I$, or scrambled siRNA and then treated with DMBX-A $(25 \mu \mathrm{M})$ for $5 \mathrm{~min}$; next, the protein expression levels of p-PKC, p-Akt, and Akt were analyzed. The data are presented as the mean \pm SEM. ${ }^{*} P<0.05$ vs. untreated cells, ${ }^{\#} P<0.05$ vs. DMBX-A-treated or DMBX-A and siRNA-treated cells 

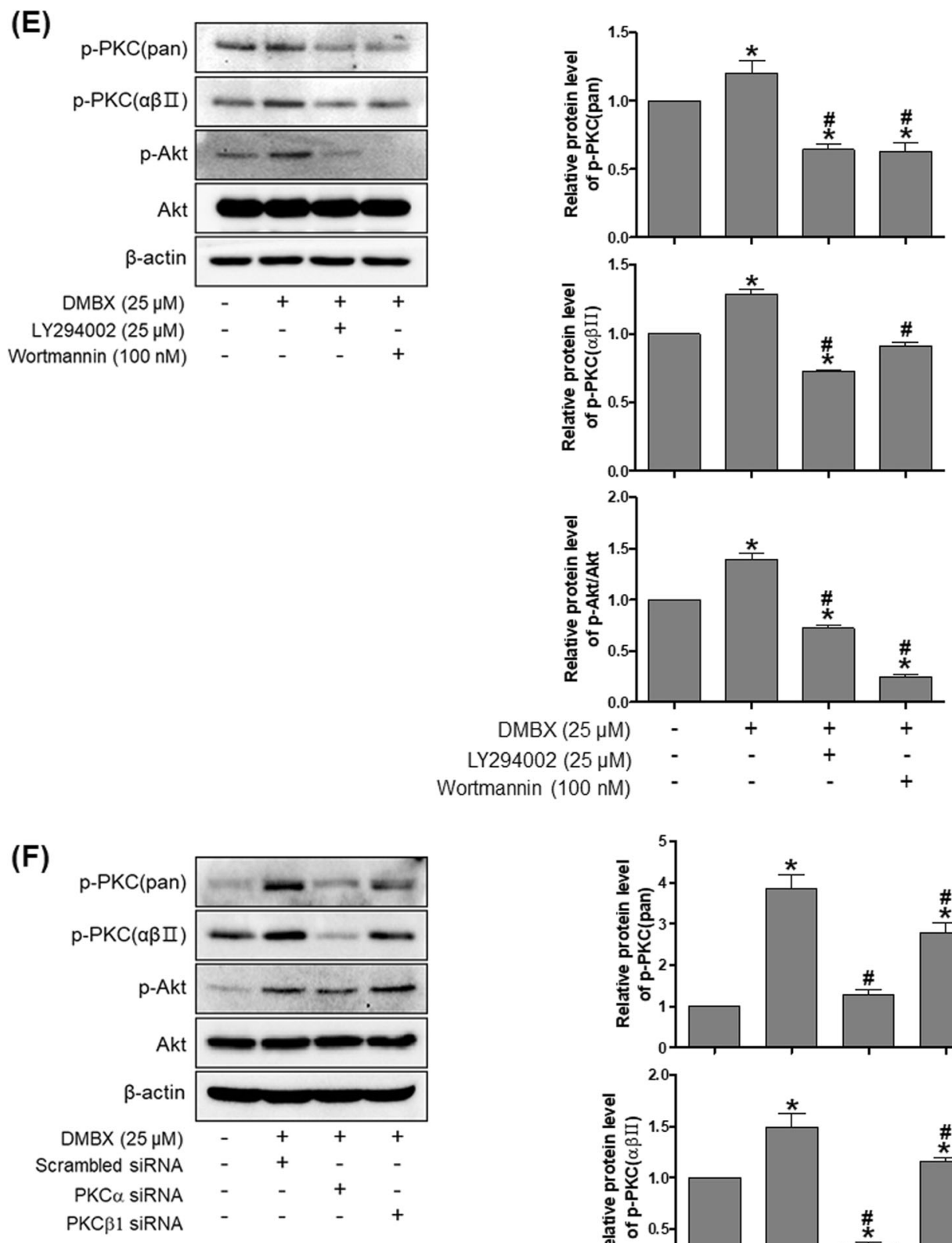

Fig. 6 Continued. 

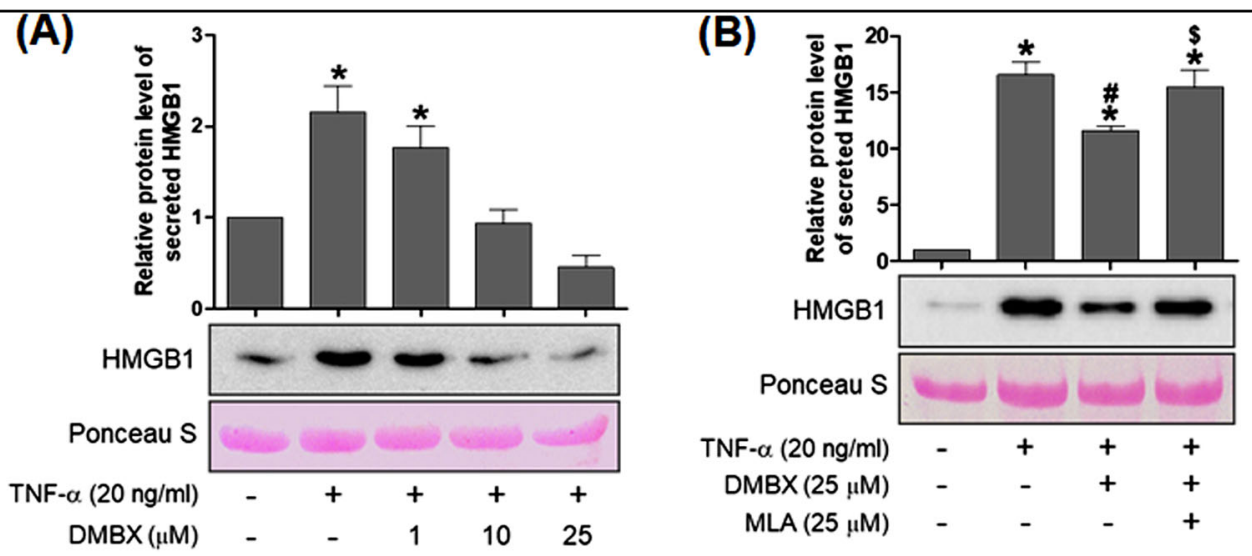

(C)

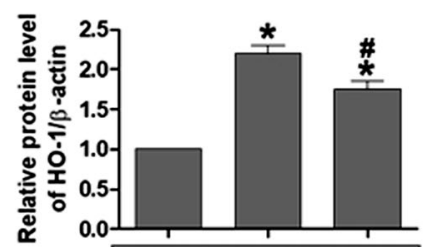

$\mathrm{HO}-1$

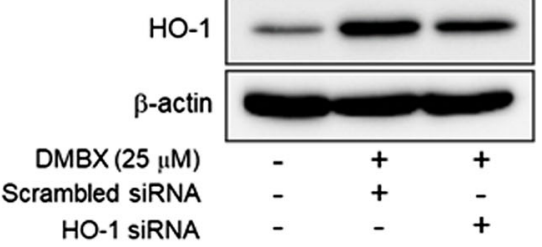

(D)
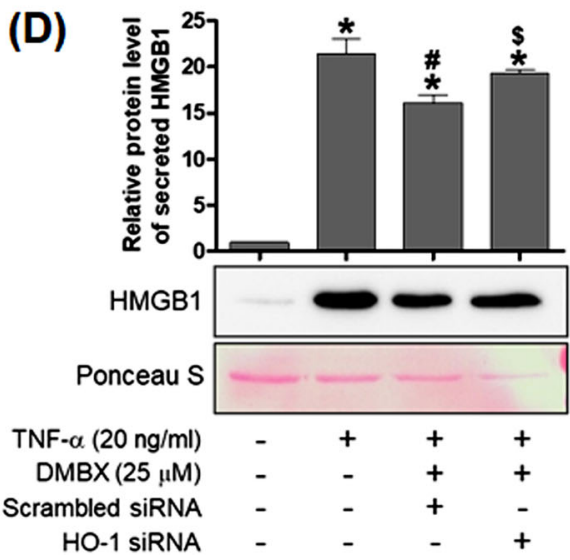

Fig. 7 a7nAChR activation decreases TNF-a-stimulated HMGB1 release through HO-1 upregulation in HK-2 cells. a, b Cells were pretreated with DMBX-A $(1,10$, or $25 \mu \mathrm{M})$ or co-treated with MLA $(25 \mu \mathrm{M})$ for $1 \mathrm{~h}$ and stimulated with TNF-a $(20 \mathrm{ng} / \mathrm{ml})$ for $24 \mathrm{~h}$. The medium was collected for western blotting with an HMGB1 antibody or Ponceau S staining. The relative protein expression levels of secreted HMGB1 were determined by using the total protein levels stained with Ponceau S and quantification. c Cells were transfected with scrambled siRNA or siHO-1 for $24 \mathrm{~h}$ and then treated with DMBX for $24 \mathrm{~h}$; next, the knockdown efficiency of HO-1 was analyzed according to the protein levels. $\mathbf{d}$ Cells were transfected with scrambled siRNA or siHO- 1 for $24 \mathrm{~h}$, treated with DMBX-A for $1 \mathrm{~h}$, and then stimulated with TNF-a $(20 \mathrm{ng} / \mathrm{ml})$ for $24 \mathrm{~h}$. The medium was collected for western blotting with an HMGB1 antibody or Ponceau $S$ staining, and the relative expression levels of secreted HMGB1 were analyzed by western blot and quantified. The data are presented as the mean \pm SEM. ${ }^{*} P<0.05$ vs. untreated cells, ${ }^{\#} P<0.05$ vs. TNF-a or DMBX-A-treated and siRNA-treated cells

in proximal tubular cells is critical for renal protection from IR injury.

Renal tubular epithelial cell injury is a key feature of the initial phase of renal IR, and vascular injury and inflammation contribute to tissue injury and the decline in renal function in the extension phase. The subsequent recovery phase is marked by a return to normal renal structure and function ${ }^{3}$. In particular, the proximal tubule contains highly metabolically active nephron segments due to the enormous level of ATP produced by mitochondrial oxidative respiration to support the massive level of active transport. Thus, proximal tubular cells are sensitive to oxidative stress and are severely damaged during various toxin-induced nephropathies ${ }^{13}$. Proximal tubular cells activate the initial inflammatory signaling by producing cytokines (e.g., IL-18 and IL-16) and an autocrine or paracrine loop of HMGB1 release ${ }^{14,15}$.
The inflammatory response is an essential body defense mechanism against various external stimuli or cellular stress; however, excessive or inappropriate inflammation results in adverse effects and is often associated with arthritis, ischemia, or metabolic disease. The $\alpha 7 \mathrm{nAChR}$ cholinergic anti-inflammatory pathway is critical for attenuating excessive inflammatory responses through vagus nerve stimulation (VNS). Activation of the afferent vagus nerve terminals transmits action potentials to the efferent vagus nerve fibers and eventually leads to macrophage $\alpha 7 \mathrm{nAChR}$ activation by acetylcholine and the suppression of proinflammatory cytokine production ${ }^{16}$. The protective effects of $\alpha 7 \mathrm{nAChR}$ activation have been reported in various animal models, and nicotinic $\alpha 7 \mathrm{nAChR}$ agonists have been suggested to pharmacologically target inflammatory diseases ${ }^{17}$. Nicotinic $\alpha 7 \mathrm{nAChR}$ activation was shown to attenuate septic renal 


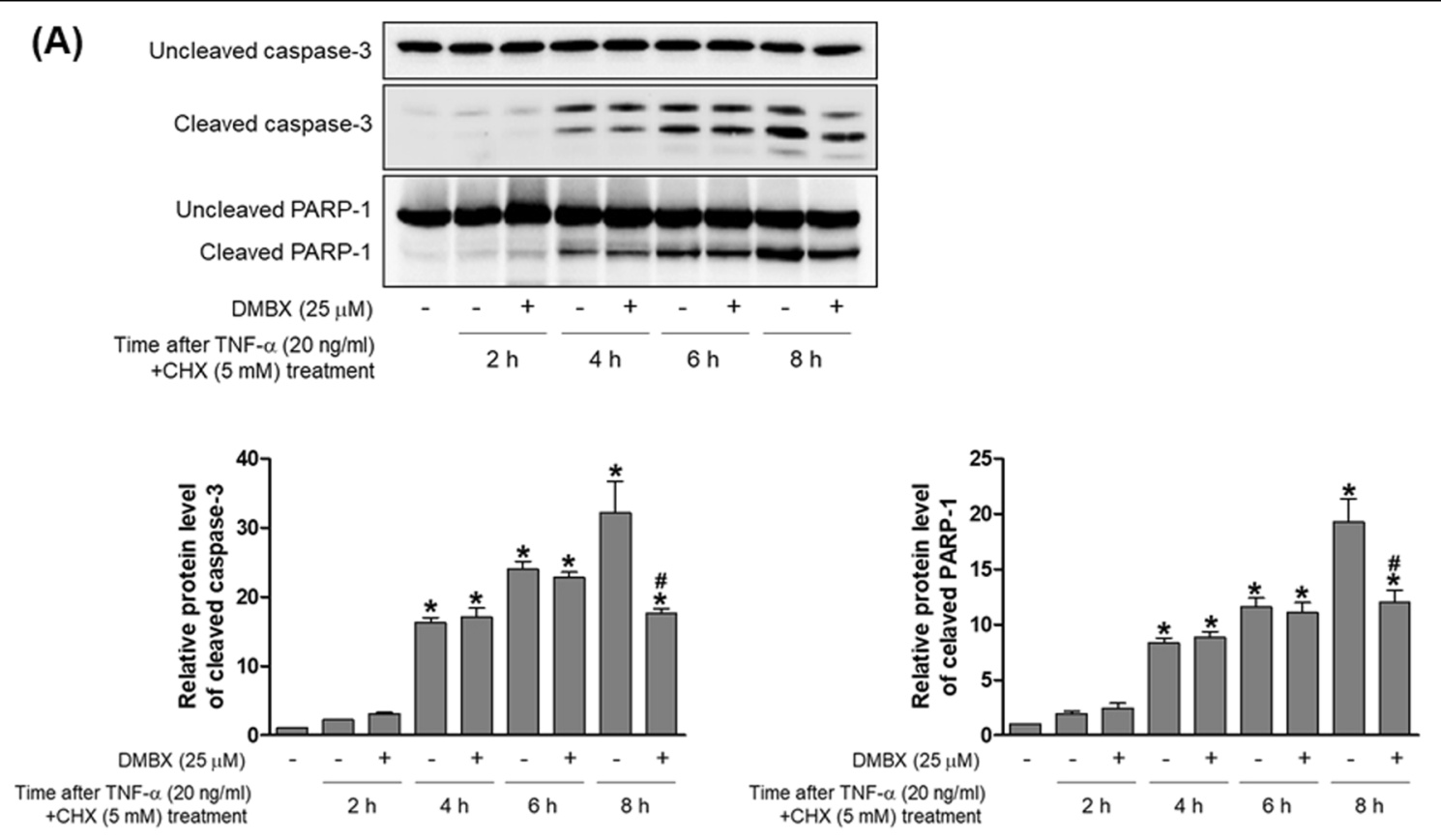

(B)
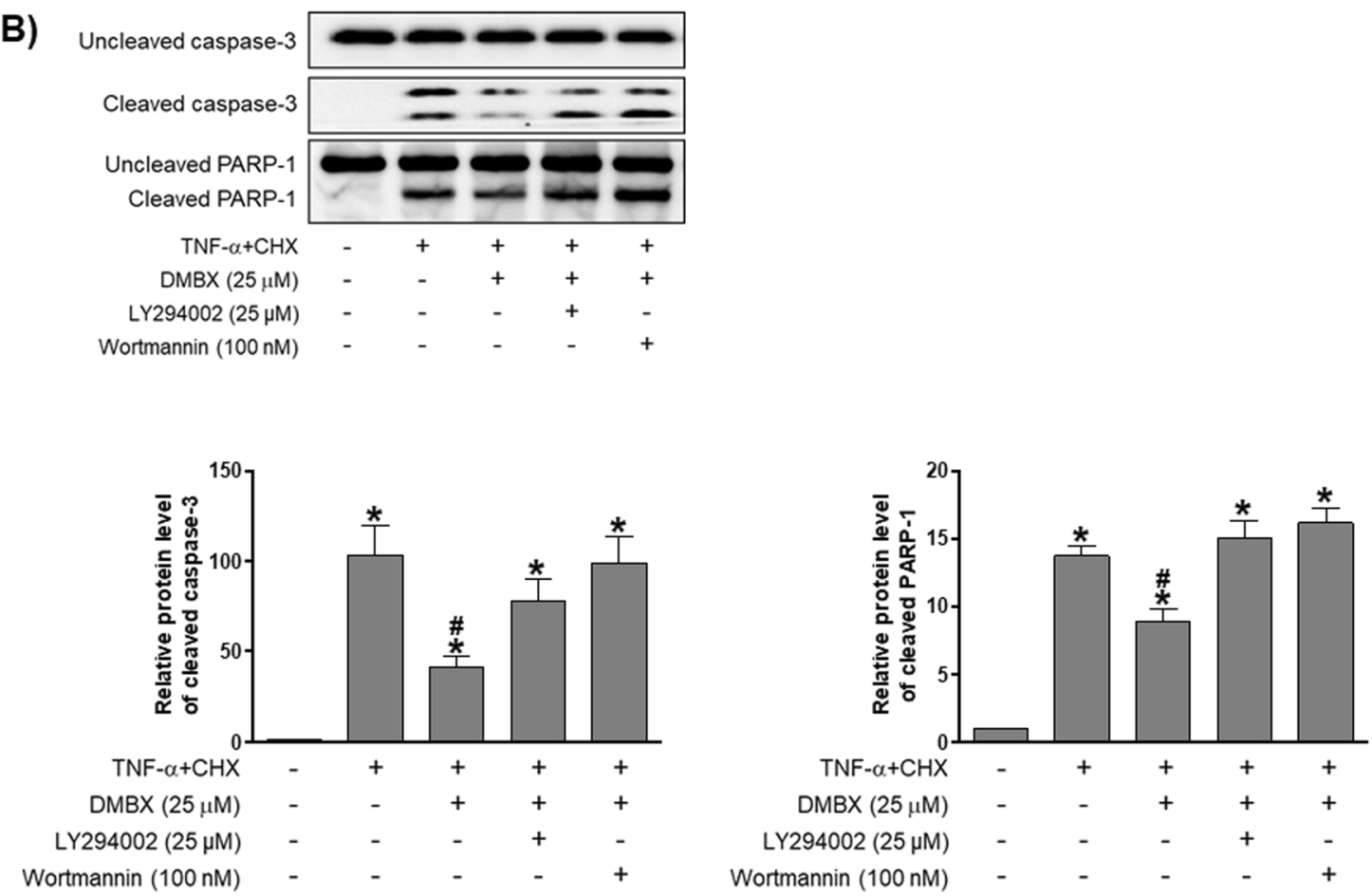

Fig. 8 a7nAChR activation decreases the TNF-a-stimulated expression of cleaved caspase-3 and cleaved PARP-1 through the PI3K/Akt signaling pathway. a Cells were pretreated with DMBX-A $(25 \mu \mathrm{M})$ for $1 \mathrm{~h}$, and then apoptotic cell death was induced by TNFa $(10 \mathrm{ng} / \mathrm{ml})$ and cycloheximide (CHX, $5 \mu \mathrm{M})$ for 2, 4, 6, or $8 \mathrm{~h}$. Caspase-3 and PARP-1 cleavage was analyzed by western blotting and quantified. b Cells were pretreated for $1 \mathrm{~h}$ with LY294002 $(25 \mu \mathrm{M})$ or wortmannin $(100 \mathrm{nM})$ before DMBX-A $(25 \mu \mathrm{M})$ treatment; after $1 \mathrm{~h}$, apoptotic cell death was induced by treatment with TNF- $a$ and CHX for $8 \mathrm{~h}$. Then, caspase-3 and PARP-1 cleavage was analyzed by western blotting and quantified. The data are presented as the mean \pm SEM. ${ }^{*} P<0.05$ vs. untreated cells, ${ }^{\#} P<0.05$ vs. TNF-a + CHX-treated cells 
inflammation in mice by suppressing NF- $\mathrm{kB}$ activation and proteasome activity ${ }^{18}$. Nicotine improved the survival rate of septic animals by attenuating the inflammatory response in macrophages ${ }^{19}$. Nicotine also attenuated renal dysfunction (e.g., reduced serum Cr levels) and tubular damage and downregulated inflammatory mediators (e.g., serum HMGB1 and TNF- $\alpha$ ) in renal IR injury ${ }^{9}$. A recent study showed that VNS was not protective against renal IR after splenectomy, but the adoptive transfer of VNSconditioned splenocytes conferred protection in recipient IR mice ${ }^{20}$. Most studies have reported that $\alpha 7 \mathrm{nAChR}$ in macrophages mediates nicotinic cholinergic activation during systemic inflammation and associated organ dysfunction. Here, for the first time, we showed a protective effect of proximal tubular $\alpha 7 \mathrm{nAChR}$ activation in renal IR injury and revealed downstream HO-1 induction. The nervous and immune systems interact and activate $\alpha 7 \mathrm{nAChR}$ in splenic macrophages, and our findings further suggest that proximal tubular $\alpha 7 \mathrm{nAChR}$ activation at the injured sites during renal IR plays a critical role in renal protection.

HO-1 catalyzes the degradation of heme to biliverdin, carbon monoxide, and free iron and is upregulated under oxidative stress $^{21}$. HO-1 induction is cytoprotective against apoptotic cell death through its anti-inflammatory properties, particularly in myeloid cells and endothelial cells $^{22}$. Myeloid-cell-specific HO-1 knockout mice exhibited a defect in interferon- $\beta$ production during the innate immune responses in experimentally induced infections $^{23}$. Endothelial protection by HO-1 was shown to be mediated by downregulating the TNF- $\alpha$-mediated expression of adhesion molecules ${ }^{24}$. In addition, HO-1deficient mice showed a significant increase in circulating HMGB1 levels in an animal model of lipopolysaccharide (LPS)-induced sepsis ${ }^{25}$. HMGB1 is a chromatin-binding protein and a necessary and sufficient late mediator of severe inflammation; the inhibition of HMGB1 release is a known therapeutic target in sepsis and lethal systemic inflammation $^{26,27}$. $\alpha 7 \mathrm{nAChR}$ agonists reduced HMGB1 production and rescued septic lethality ${ }^{28}$. Here, we proposed that the proximal tubular-specific induction of $\mathrm{HO}$ 1 by $\alpha 7 n A C h R$ activation is critical for protecting against IR-induced renal inflammation by reducing HMGB1 release.

A previous study showed that the intravenous injection of macrophages expressing HO-1 into renal IR mice improved renal function (as demonstrated by a reduction in serum Cr levels) and reduced microvascular platelet deposition; however, no effects on acute tubular cell death or serum cytokine levels were seen compared to control mice ${ }^{29}$. This indicates that macrophage-derived HO-1 induction preserves renal function but is not sufficient to attenuate IR-induced systemic inflammation or tubular damage. We propose in this study that the proximal tubular induction of $\mathrm{HO}-1$ by $\alpha 7 \mathrm{nAChR}$ activation is critical for protecting against renal inflammation and tubular cellular damage.

The mechanisms by which $\alpha 7 \mathrm{nAChR}$ activation regulates inflammation and cellular damage are under intensive investigation, and potential molecular mechanisms have been proposed ${ }^{30}$. Nicotine administration in animal models of sepsis reduced HMGB1 levels and improved survival by inhibiting NF- $\mathrm{KB}$ activation; ${ }^{8}$ nicotine also suppressed NF- $\mathrm{KB}$ transcriptional activity in LPS-stimulated human peripheral monocytes ${ }^{31}$. Nicotinic stimulation of $\alpha 7 \mathrm{nAChR}$ attenuated macrophage activation via the tyrosine kinase Janus kinase 1 (JAK2)-induced signal transducer and activator of transcription 3 signaling pathway ${ }^{32}$. In neuronal cells, $\alpha 7 \mathrm{nAChR}$ activation induces JAK2-mediated signaling and protects neuronal loss from $\beta$-amyloid-induced cytotoxicity ${ }^{33,}{ }^{34}$. Recently, the nicotinic stimulation of $\alpha 7 \mathrm{nAChR}$ in macrophages improved the survival of septic mice through HO-1 induction ${ }^{19}$. In LPS-activated macrophages, $\alpha 7 \mathrm{nAChR}$ mediated the induction of $\mathrm{HO}-1$ via protein kinase $\mathrm{A}$ activation and stimulated PI3K and p38 MAPK activity; the resultant nuclear factor (erythroid-derived 2)-like 2 translocation activated HO-1 expression ${ }^{35}$, 36 . Our study showed that $\alpha 7 \mathrm{nAChR}$ mediated HO-1 induction through PI3K/Akt and PKC signaling in renal proximal tubular cells and that the PI3K/Akt activity was upstream of the PKC activity. However, it is not known which signaling mediators of $\alpha 7 n A C h R$ (e.g., cAMP or $\mathrm{Ca}^{2+}$ ) activate PI3K/Akt signaling in renal IR. Additionally, the downstream PKC molecules that activate $\mathrm{HO}-1$ transcription remain to be identified.

In this study, we showed that proximal tubular $\alpha 7 \mathrm{nAChR}$ activation protected the kidney from IRinduced inflammation and tubular cell death via the HO-1-mediated inhibition of HMGB1 release. In particular, we described a molecular mechanism whereby PI3K/Akt and PKC signaling are involved in $\alpha 7 n A C h R-$ mediated HO-1 induction. We propose that the proximal tubular activation of $\alpha 7 \mathrm{nAChR}$ and its regulatory mechanism would be a promising therapeutic target for treating ischemic acute kidney injury.

\section{Acknowledgements}

The sources of support were the Basic Science Research Program through the National Research Foundation (NRF) of Korea funded by the Ministry of Science, ICT, and Future Planning (NRF-2015R1A5A2008833 and NRF2017R1A2B4009387).

Conflict of interest

The authors declare that they have no conflict of interest. 


\section{Publisher's note}

Springer Nature remains neutral with regard to jurisdictional claims in published maps and institutional affiliations.

Supplementary information accompanies this paper at https://doi.org/ 10.1038/s12276-018-0061-x.

Received: 4 August 2017 Revised: 20 December 2017 Accepted: 3 January 2018.

Published online: 20 April 2018

\section{References}

1. Lameire, N., Van Biesen, W. \& Vanholder, R. The changing epidemiology of acute renal failure. Nat. Clin. Pract. Nephrol. 2, 364-377 (2006).

2. Abdel-Kader, K. \& Palevsky, P. M. Acute kidney injury in the elderly. Clin. Geriatr. Med. 25, 331-358 (2009).

3. Basile, D. P., Anderson, M. D. \& Sutton, T. A. Pathophysiology of acute kidney injury. Compr. Physiol. 2, 1303-1353 (2012).

4. Wang, $\mathrm{H}$. et al. Nicotinic acetylcholine receptor alpha7 subunit is an essential regulator of inflammation. Nature 421, 384-388 (2003).

5. Borovikova, L. V. et al. Vagus nerve stimulation attenuates the systemic inflammatory response to endotoxin. Nature 405, 458-462 (2000).

6. Pavlov, V. A. Cholinergic modulation of inflammation. Int J. Clin. Exp. Med. 1, 203-212 (2008).

7. Saeed, R. W. et al. Cholinergic stimulation blocks endothelial cell activation and leukocyte recruitment during inflammation. J. Exp. Med. 201, 1113-1123 (2005).

8. Wang, $\mathrm{H}$. et al. Cholinergic agonists inhibit $\mathrm{HMGB1}$ release and improve survival in experimental sepsis. Nat. Med. 10, 1216-1221 (2004).

9. Sadis, C. et al. Nicotine protects kidney from renal ischemia/reperfusion injury through the cholinergic anti-inflammatory pathway. PLOS ONE 2, e469 (2007).

10. Maines, M. D. The heme oxygenase system: a regulator of second messenger gases. Annu. Rev. Pharmacol. Toxicol. 37, 517-554 (1997).

11. Jablonski, P. et al. An experimental model for assessment of renal recovery from warm ischemia. Transplantation 35, 198-204 (1983).

12. Malek, M. \& Nematbakhsh, M. Renal ischemia/reperfusion injury; from pathophysiology to treatment. J. Ren. Inj. Prev. 4, 20-27 (2015).

13. Ratliff, B. B., Abdulmahdi, W., Pawar, R. \& Wolin, M. S. Oxidant mechanisms in renal injury and disease. Antioxid. Redox Signal. 25, 119-146 (2016).

14. Akcay, A., Nguyen, Q. \& Edelstein, C. L. Mediators of inflammation in acute kidney injury. Mediat. Inflamm. 2009, 137072 (2009).

15. Chen, Q., Guan, X., Zuo, X., Wang, J. \& Yin, W. The role of high mobility group box 1 (HMGB1) in the pathogenesis of kidney diseases. Acta Pharm. Sin. B 6, 183-188 (2016).

16. Tracey, K. J. Physiology and immunology of the cholinergic antiinflammatory pathway. J. Clin. Invest. 117, 289-296 (2007).

17. de Jonge, W. J. \& Ulloa, L. The alpha7 nicotinic acetylcholine receptor as a pharmacological target for inflammation. Br. J. Pharmacol. 151, 915-929 (2007).

18. Chatterjee, P. K. et al. Nicotinic acetylcholine receptor agonists attenuate septic acute kidney injury in mice by suppressing inflammation and proteasome activity. PLoS ONE 7, e35361 (2012).
19. Tsoyi, K et al. Stimulation of alpha7 nicotinic acetylcholine receptor by nicotine attenuates inflammatory response in macrophages and improves survival in experimental model of sepsis through heme oxygenase-1 induction. Antioxid. Redox Signal.14, 2057-2070 (2011).

20. Inoue, $T$. et al. Vagus nerve stimulation mediates protection from kidney ischemia-reperfusion injury through alpha7nAChR + splenocytes. J. Clin. Invest. 126, 1939-1952 (2016).

21. Maines, M. D. Heme oxygenase: function, multiplicity, regulatory mechanisms, and clinical applications. FASEB J. 2, 2557-2568 (1988).

22. Paine, A., Eiz-Vesper, B., Blasczyk, R. \& Immenschuh, S. Signaling to heme -oxygenase-1 and its anti-inflammatory therapeutic potential. Biochem. Pharmacol. 80, 1895-1903 (2010).

23. Tzima, S., Victoratos, P., Kranidioti, K., Alexiou, M. \& Kollias, G. Myeloid heme oxygenase-1 regulates innate immunity and autoimmunity by modulating IFN-beta production. J. Exp. Med. 206, 1167-1179 (2009).

24. Soares, M. P. et al. Heme oxygenase-1 modulates the expression of adhesion molecules associated with endothelial cell activation. J. Immunol. 172, 3553-3563 (2004)

25. Takamiya, R. et al. High-mobility group box 1 contributes to lethality of endotoxemia in heme oxygenase-1-deficient mice. Am. J. Respir. Cell. Mol. Biol. 41, 129-135 (2009).

26. Wang, $\mathrm{H}$. et al. HMG-1 as a late mediator of endotoxin lethality in mice. Science 285, 248-251 (1999).

27. Wang, H., Yang, H., Czura, C. J., Sama, A. E. \& Tracey, K. J. HMGB1 as a late mediator of lethal systemic inflammation. Am. J. Respir. Crit. Care Med. 164, 1768-1773 (2001)

28. Huston, J. M. et al. Transcutaneous vagus nerve stimulation reduces serum high mobility group box 1 levels and improves survival in murine sepsis. Crit. Care Med. 35, 2762-2768 (2007).

29. Ferenbach, D. A. et al. Macrophages expressing heme oxygenase- 1 improve renal function in ischemia/reperfusion injury. Mol. Ther. 18, 1706-1713 (2010).

30. Baez-Pagan, C. A., Delgado-Velez, M. \& Lasalde-Dominicci, J. A. Activation of the macrophage alpha7 nicotinic acetylcholine receptor and control of inflammation. J. Neuroimmune Pharmacol. 10, 468-476 (2015).

31. Thorndike, F. P., Wernicke, R., Pearlman, M. Y. \& Haaga, D. A. Nicotine dependence, PTSD symptoms, and depression proneness among male and female smokers. Addict. Behav. 31, 223-231 (2006).

32. de Jonge, W. J. et al Stimulation of the vagus nerve attenuates macrophage activation by activating the Jak2-STAT3 signaling pathway. Nat. Immunol. $\mathbf{6}$ 844-851 (2005)

33. Marrero, M. B. \& Bencherif, M. Convergence of alpha 7 nicotinic acetylcholine receptor-activated pathways for anti-apoptosis and anti-inflammation: central role for JAK2 activation of STAT3 and NF-kappaB. Brain Res. 1256, 1-7 (2009).

34. Shaw, S., Bencherif, M. \& Marrero, M. B. Janus kinase 2, an early target of alpha 7 nicotinic acetylcholine receptor-mediated neuroprotection against Abeta-(142) amyloid. J. Biol. Chem. 277, 44920-44924 (2002).

35. $\mathrm{Ha}, \mathrm{Y} . \mathrm{M}$. et al. Beta(1)-adrenergic receptor-mediated $\mathrm{HO}-1$ induction, via PI3K and p38 MAPK, by isoproterenol in RAW 264.7 cells leads to inhibition of HMGB1 release in LPS-activated RAW 264.7 cells and increases in survival rate of CLP-induced septic mice. Biochem. Pharmacol. 82, 769-777 (2011).

36. Sun, J. et al. Selective activation of adrenergic beta1 receptors induces heme oxygenase 1 production in RAW264.7 cells. FEBS Lett. 579, 5494-5500 (2005). 